\title{
III.
}

\section{Über Erscheinungen und Grundlagen der Woṛtanbheit.}

Von

\section{Privatdozent Dr. F. Quensel.}

(Mit 2 Abbildungen.)

Im Folgenden gebe ich einige von mir genau beobachtete Fälle von Worttaubheit wieder, von denen zumal der erste ein besonderes Interesse verdient, während die beiden anderen mehr ein Vergleichsmaterial darstellen. Aus äusseren Gründen muss ich mich bei dem ersten Falle bezüglich der Autopsie beschränken auf eine Wiedergabe des makroskopischen Befundes, hoffe aber, dass auch der mikroskopische in absehbarer Zeit zur Darstellung gelangen wird, da er eine wertvolle Ausbeute verspricht. Nachdem ich selbst mich anderweit ${ }^{118}$ ) mit der feineren Anatomie der in Betracht kommenden Gegend schon beschäftigt habe und der makroskopische Befund in mancher Richtung bereits ziemlich klar und beweisend ist, schien es mir lohnend, neben ihm zusammenzustellen, was eine genaue Durchsicht der Literatur zusammen mit meinen eigenen auf diesem Gebiete ziemlich ausgedehnten Erfahrungen für Schlüsse zu ziehen gestattet. Ich habe über 200 einschlägige Beobachtungen von Worttaubheit zumeist im Original durchgearbeitet. Auf Vollständigkeit erhebt meine Zusammenstellung keinen Anspruch, bei der grossen Zerstreuung des Materials in der Literatur und aus anderen Gründen war mir eine Vervollständigung nicht möglich. Die Art des Materials bringt es mit sich, dass unsere Schlüsse heute noch in vielen Punkten keine zwingende Beweiskraft haben können. Ich möchte dieselben daher auch nicht allenthalben als bindend ansehen, glaube aber, dass sie durchaus gestatten, unsere Fragestellungen zu präzisieren und gewisse Beiträge zum Verständnis des Mechanismus der Worttaubheit zu liefern im Gegensatz zu manchen heute noch festgehaltenen schematischen Anschauungen.

Fall 1*). M . . ., August, Tischler, geboren 30. III. 1861, aufgenommen 8. VI. 1907.

*) Krankenvorstellung in der med. Gesellschaft zu Leipzig am 9. VII. 1907. Münch. med. Wochenschr. 1907. S. 1752. 
Nicht belastet, zum zweiten Mal verheiratet seit 1899 . In der ersten Ehe drei gesunde Kinder, eins skrophulös, in zweiter Ehe ein gesundes Kind, ein Abort der Frau im zweiten Monat.

Früher nicht erheblich krank gewesen, nicht Soldat wegen zu schwacher Brust. Hat nicht getrunken.

X. 1905 erkrankt an "Herzerweiterung".

Vor ca. $1 \%$ Jahren hatte Pat. einen "Anfall", konnte 2 Tage lang nicht reden, Lähmungserscheinungen usw. bestanden nicht. Er erholte sich wieder und konnte leichte Arbeit übernehmen.

Am 18. V. 1907 exkrankte er wieder mit Atemnot und Bruststechen. Während er früher gut gehört hatte, hörte er jetzt nicht mehr darauf, wenn man etwas zu ihm sagte, und fing an „irre zu reden". Lähmungen oder Krămpfe bestanden nicht.

Er war dann 10 Tage im Krankenhaus zu St. Jaǩob. Nach Angabe der Frau hat er erst dort die Sprache ganz und gar verloren, während es früher zeitweilig besser war. Er war unruhig, blieb nicht im Bett, wollte immer auf Arbeit gehen, so dass er am 8. VI. 1907 in die psych. und Nervenklinik verlegt wurde.

Stat. somaticus: Schlanker, schmächtiger Mann mit leichter Kypho skoliose. Muskulatur schwach, Fettpolster sehr gering. An Wange, Nasenspitze, überhaupt im Gesicht, an den Extremitätenenden deutliche Cyanose. Brust flach. Herzdämpfung überragt den linken Sternalrand nach rechts kaum, reicht nach links über die Mammillarlinie hinaus. Systolisches Geräusch uber der Aorta sehr deutlich. Puls 120 p. M. von geringer Füllung und Spannung. Deutliche Sklerose der Aa. radiales und temporales.

Es besteht deutliche Dyspnoe. Leichte Dämpfung und abgeschwächtes Atmen über dem linken Unterlappen.

Abdomen 0. B. Urin frei von S. und A. Pupillen gleich, von guter Reaktion. Der rechte Mundwinkel steht in der Ruhe und beim Mundöffnen vielleicht etwas tiefer. Sonst finden sich keinerlei Lähmungserscheinungen von seiten der Hirnnerven oder an den Extremitäten. Es besteht kein Tremor, keine Ataxie. Haltung und Gang normal, kein Rombergsches Phänomen. Patellar-, Achilles-, Anconaeus-Reflex normal, beiderseits gleich. Haut- und Schleimhautreflexe normal. Sensibilität für Berührungen und schmerzhafte Nadelstiche überall normal.

Das Gesichtsfeld wurde am Perimeter mit zwei elektrischen Lampen geprüft. Pat. fixierte den Mittelpunkt sehr gut und markierte jedes Erscheinen der elektrischen Lampe mit "Karl Meyer", und zwar absolut prompt in allen Quadranten auf beiden Augen. Genauere Prüfung war nicht ausführbar.

Gehör: Pat. hört Flüsterstimme rechts in $50 \mathrm{~cm}$, links in $20 \mathrm{~cm}$.

Es besteht bei ihm eine aphasische Sprachstörung, deren Erscheinungen während der ganzen Beobachtungsdauer so geringe Schwankungen aufweisen, dass es gestattet erscheint, dieselben im Folgenden zusammenzufassen.

Sprachverständnis: Von Beginn an fiel auf, dass Pat., der auf alle Geräusche achtete, sofort wieder klopfte, wenn man hinter seinem Rücken an die Wand klopfte, beim Klingeln des Telephons ausrief: "fein" usw., absolut nicht auf Fragen reagierte. Er schien auch durchaus gewillt, Aufforderungen nachzukommen, verstand jedoch offenbar absolut nicht, was man von ihm wollte. Bei zahlreichen eingehenden Prüfungen sind nur ganz 
vereinzelte spärliche Zeichen eines Restes von Wortverständnis bei ihm beobachtet worden.

Am besten war dasselbe am 16. VI. 1907. Er reagierte auf: Wie heissen Sie? "Wie, ich? August Meyer Friedrichstrasse." Was sind Sie? "Friedrichstrasse, Friedrich-la - Friedrichstrasse." Was sind Sie? "Jetzt bin ich en Fahrstuhl eme a will ich nur heut Abend mit enar." Sind Sie verheiratet? Nickt. "Frau - ja." Wie heisst Ihre Frau? "Meine Frau, ja." Wieviel Kinder haben Sie? "Und noch, Alles, Alles sind 13 und 6 Ostern, die Ostern, Ostern erst denks her dann." Wer bin ich? "Was sind wir, ich bin, meine Mutter hands das Meyer."

Absolut unmöglich war es, ihn auch durch wiederholte Aufforderungen zu irgend einer Bewegung zu bringen: "Zunge zeigen, Augen zumachen; heben Sie die rechte Hand hoch usw." Er zeigte für diese Aufforderungen keinerlei Verständnis. Dabei war er, wie noch gezeigt werden wird, sehr wohl imstande den gleichen Aufforderungen, wenn man sie mimisch an ihn richtete, nachzukommen.

Am 17. VI. reagierte er nicht, oder nur sinnlos auf die Fragen: Was sind Sie? wie heissen Sie? auf Aufforderungen: Stehen Sie auf! Zunge zeigen! oder von vorgelegten Gegenständen auf Namensnennung zu reichen, Uhr, Portemonnaie, Streichbölzer usw. Nur auf die Frage: Sind Sie krank? erfolgte: "Ich bin nicht, wenn Sie - wenn ich, hier schleints, Herz hier, nicht wahr"? (zeigt auf die linke Brustseite) - „ich war e Mann, war je manche hier".

Am 18. VI. antwortete er zu Beginn richtig auf: Wie heissen Sie? "August Meyer, ja". Wo wohnen Sie? "Friedrichstrasse, hier". Wie gehts? "Ich ja". Wie alt sind Sie? "46 Jahre". Weiterhin aber reagierte Pat. auf" keine Frage, keine Aufforderung oder sonstige Anrede richtig. (Aufstehen! Zunge zeigen! Augen zu! Haben Sie Kinder? Wie heisst Ihre Frau? Kann ein Walfisch fliegen? "Mittag, Mittag, richtig, wenn Sie." - Sie haben eine grüne Nase! Sie haben gestohlen! Geben Sie mir die Flasche, die Scheere! usw.)

Endlich hat er am 9. VII. im Beginn der Exploration die Frage: Wie heissen Sie? richtig beantwortet. Bei weiteren Fragen wie auch sonst stets bei wiederholten Befragungen, z. B. vom 2. V., 11. VII. und zumal, sobald man ihm nicht derartige erwartete Fragen vorlegte, versagte er vollkommen. Da er Aufforderungen mimischer Art gut befolgte, kann man also sagen, das Wortsinnverständnis war wohl zunächst noch in Spuren vorhanden, späterhin so gut wie vollständig aufgehoben und zwar bis zuletzt.

Dagegen war das Wortlautverständnis bis zu einem gewissen nicht unerheblichen Grade erhalten. Es bewies das die Fähigkeit des Nachsprechens. Wenn Pat. hierbei einmal ganz versagte, wie am 16. VI., so war das sicher nachweisbar die Folge störender Momente, wie einer hartnäckigen Perseveration. Die Resultate sonst, zwar nicht in absoluter Übereinstimmung, geben doch ein hinreichend scharf umschriebenes Bild. Einsilbige Worte sprach er meist, bisweilen auch geläufige und leichte zweisilbige richtig nach. Schwieriger waren ihm einsilbige Worte, wenn ein Doppelkonsonant darin vorkam, oder wenn ihm dieselben ferner lagen. Bei solchen, bei der Mehrzahl der zweisilbigen produzierte er paraphasisch entstellte Leistungen, welche dem richtigen Worte partiell entsprachen, bei 
mehrsilbigen entgleiste er stets und brachte höchstens die erste Silbe richtig heraus. Dabei machte es keinen Unterschied, wenigstens bei hinreichender Aufmerksamkeit, ob er nach dem Munde des Sprechenden sah, oder ob man ihm bei verdeckt gehaltenem Munde vorsprach.

So repetierte er richtig am 17. VI.: Vater, Ohr, Bett, Aal; es misslangen ihm: Stuhl $=$ "Saron, Sokol", Kreuz = zuerst: "Mein tol", dann + . Zunge $=$ "Zor-e-ne, Zunger", Apfel $=$ "Ampfel", Berlin $=$ "Om-berne", Klinik $=$ "nicht klinge", Mantel $=$ „Mantl", Strohhut $=$ „Montunge, Stroh hier", Portemonnaie $=$ "Porgot noch Kann ich".

Am 18. VI. richtig Ohr, Stuhl, Hut, dagegen Apfel = "Apfelig", Lampe $=$ "Lampif", Jacke $=$ "Jacketif", Fensterbrett $=$ „Fensterventer", Apfelbaum $=$ "Ampfelev".

Durch sein Nachsprechen von Worten, wie dumm und faul, auf die er übrigens absolut nicht reagjerte, oder von Zahlworten, die er gut wiederholte, gelang uns auch der Nachweis, dass und inwieweit er noch Flüsterstimme vernahm.

Er hat auch später, z. B. am 21, auch am 29. VI. gelegentlich wieder infolge seiner Aufregung versagt, brachte z. B. statt Tisch $=$ "Bele", Frau $=$,Ja. Frauen ich kannen vornen, vronnen, hier will ich ohnen Fraun", Bett $=$,ich bennen".

Die gleichen Worte gelangen ihm aber am 30. VI. und späterhin wieder, ebenso andere: Vogel $=$,Vögel ", Kopf $=$,Vogel, Kopfel ", Brot +, Leipzig + +, Uhr + , Drücker $=$ "Drückel"; er konnte so am 9. VII. in der medizinischen Gesellschaft vorgestellt werden und änderte sich nicht bis zuletzt.

Wir haben mehrfach versucht, Gehör, Verständnis und Wiederholungsfähigkeit auch auf musikalischem Gebiete zu prüfen, wobei dem Pat. vorgesungen oder vorgepfiffen warde.

Am 6. VII. beachtete er Pfeifen zunächst überhaupt wenig, nach einiger Zeit auf Aufmunterung sagte er: "Ich so'n Ton", machte auch Taktbewegungen, schien es also als Melodie im allgemeinen zu erkennen. Er begann dann sogar in halb sprechender Weise etwas vorzusingen, doch war seine Leistung ohne jede Ähnlichkeit mit der vorgepfiffenen Melodie und überhaupt ohne erkennbaren Sinn. Einzelne Töne waren bisweilen richtig.

Am 11. VII. musste es zweifelhaft bleiben, ob er eine ihm sicher von früher bekannte Melodie überhaupt als solche erkannte, er nickte wohl, war aber nicht zum Nachsingen oder Pfeifen zu bewegen.

Das zumeist in die Augen fallende Sympton ist die mangelnde Sprechfâhigkeit des Pat, Als ein echt sensorisch Aphasischer sprach er sehr viel, nicht zu allen Zeiten, stets jedoch, wenn er angeregt war und wenn er in Affekt geriet. Aber auch ohne erkennbaren äusseren Anlass hatte er Wochen, in denen er durch sein Jammern und Schwatzen, durch eine echte Logorrhoe lästig fiel, so dass es nötig wurde, ihn im Einzelzimmer zu belassen. Auch hier gab jeder Eintretende und Vorübergehende den Anstoss zu einem neuen Redestrom. Seine Spon tansprache charakterisiert sich sonst in erster Linie durch Wortarmut und durch unvollkommene Satzbildung. Namentlich an konkreten Hauptworten, aber auch an Adjektiven prägnanter sinnlicher Bedeutung sind in der ganzen Zeit spontan von ihm nur einige wenige, wie einmal Kaffee, Uhr, Zunge oder der Satz: „Es ist kalt hier", hervorgebracht. Auch bei solchen liess sich einige Male 
erweisen, dass er sie kurz zuvor gehört and nachgesprochen hatte. Die Unvollkommenheit der Satzbildung ergibt sich nun schon aus der amnestischen Störung. Daneben machen sich aber noch andere, z. T. auch davon abhängige Faktoren geltend, zunächst eine Paraphasie. In den seltensten Fällen bringt Pat. statt der erforderlichen Worte andere in sich richtig gebildete, meist verstümmelt er dieselben, z. T. so hochgradig, dass er nur mangelhaft artikulierte Laute hervorbringt und völlig unverständlich ist. Endlich macht sich oft eine hochgradige Perseveration unangenehm bemerkbar, so dass er von ursprünglich richtigen, aber auch falschen Leistungen nicht wieder herunterkommt. Alle diese Störungen finden sich an den verschiedenen Tagen in wechselnder Weise ausgesprochen, es kann aber von keiner durchgreifenden, konstanten oder auch nur in gleicher Richtung fortschreitenden Änderung in der ganzen Beobachtungszeit die Rede sein.

So fanden wir schon beim Eintritt seine Sprache, von einzelnen Worten abgesehen, unverständlich.

Eine Probe vom 17. VI. lautet: "Ich bin doch hier unten, na wenn ich gewesen bin, ich weess nicht, wie das, nu wenn ich, ob das nun och noch, ja. - Wos Sie her, wenn ich, och ich weess nicht, wie das hier war, ja - wie, das hier, weiss ich nicht" usw. usw.

Charakteristisch sind z. B. auch die oben wiedergegebenen Antworten auf Fragen.

Am 23. VI. ist die Sprache in einer unruhigeren Zeit noch schlechter, z. B.: "For sie bei end er wurd und und es Kind wurd und der ist nach acht alt and allent - denn hier ist nicht an schlacht, der ist tot, ich kanns nicht alles machen, ich dacht in werna, was hier gleich ol wol ich doch ol, denn ich wurd und wert ich muss wort, ich wills nicht, wehl wird nicht wehr" usw. usw.; "nach nicht ein müssen matzig, katzig, dreussig - aber heut Milch nicht, olet wolet entschnulet mut, wenn ich mal faren haben hieret erret isset, bisset, ich nur, dir bissa nischt."

Am 5. VII. produzierte er folgende Leistung. Aufgefordert, die rechte Hand zu geben, zeigte er auf den Mund und sagte: "rut - ich denke hier die Zungen - ich kann hier nicht an denken, nur nichts hier, big hier, ich habe auch ein Sohn, das ist meine Annan, das die Trasse, Tasse und Rehnen" usw.

Schon aus diesen Leistungen erhellt ja, dass eine motorische Aphasie nicht vorlag. Gegen eine solche spricht auch die Fähigkeit der Reihenproduktion. Auf blosse Aufforderung, zu zäblen, versagte Pat. natürlich, begann man aber ihm langsam Wort für Wort vorzusprechen "1, 2, 3", so zählte er flott und richtig z. B. einmal bis 8 , dann mit gelegentlicher Einhilfe bis zu 20. Nicht so gelang ihm am gleichen Tage, am 17. VI. 1907, das Alphabet, perseveratorisch fiel er stets in die Zahlenreihe zurück; auch die Wochentage kamen nur z. T. etwa: "Montag, Dienstag, Freitag, 11, 12" oder "Montag, Dienstag, Freitag, Fünftag, Sechstag" usw. An anderen Tagen, z. B. am 19. VI. gelangen aber die Wochentage tadellos und das Gleiche liess sich wiederholt konstatieren. Von einer Artikulationsstörung war nicht im mindesten die Rede.

Um so klarer ist die amnestische Störung beim Versuche, Pat. Gegenstände benennen zu lassen. Unter zahlreichen (ca. 50-60) protokollierten Versuchen dieser Art hat unser Kranker nur sechsmal den richtigen Namen 
nennen können, nämlich je einmal für Bleistift und Kreide, je zweimal für Schlüssel und Uhr. Dabei war es völlig gleichgültig, ob Pat. die Gegenstände nur ansah, oder ob er sie zugleich fühlte, oder ob er sie an charakteristischen Geräuschen erkannte; nur ein einziges Mal benannte er die Uhr, nachdem er sie hatte ticken hören. Auch eindeutig und einsinnlich bestimmte Objekte und Vorgänge, wie die Farben beim Sehen, Pfeifen beim Anhören, ebenso eine Stimmgabel, Kork, Wolle oder Wasser beim Tasten, zeigten keinerlei Vorzüge in der Benennbarkeit.

Dabei erkannte er alle die vorgelegten Gegenstände ohne jede Schwierigkeit und vermochte ihren Gebrauch zu demonstrieren, auch nach den zuführenden Sinnesgebieten war er in der Erkennung nicht beschränkt.

Bei seiner Art, zu benennen, ist zu berücksichtigen, dass dieselbe absolut nicht konstant ist, die gleichen Gegenstände werden bald bezeichnet, bald nicht und zwar unmittelbar nacheinander. Verfehlte er den richtigen Namen, so gelang es in der Regel auch bei weiteren Versuchen nicht besser. Im Gegenteil macht sich nicht selten eine Perseveration der ersten falschen oder auch früherer richtiger Leistungen störend bemerkbar, so, wenn er erst die Uhr richtig, dann auch Schere und Schlüssel als "Uhr" bezeichnete. Oder er nannte Rot erst "Ros", dann Blau "Ros", Gelb $=$ „Reis" usw.

In der Mehrzahl der Fälle brachte er eine Verstümmelung des richtigen Wortes, die aber noch deutliche Anklänge darbot. So benannte er Schlüssel „Schlüsschen", Uhr „Uhrschluss", Schere "Klere", Uhr "Uhretinge“. Oder er fügte dann auch längere Sätze an, z. B. Portemonnaie = „Das ist mort alles so wohl, das ist mortmon", Streichhölzer: "Das ist Streik eintlich, ach so, wenn ich ganz, ich weiss nicht eintlich", Ring ,ein Kuting" usw. Mehrfach waren die Bezeichnungen völlig sinnlos, wie Buch "Porsten, weiss nicht", Wolle "Kassetaun", Stimmgabel "Jültesswohl", „zollig, wollig"; ebenso oft liess er Bezeichnungen ganz aus und nur in einer kleinen Zahl von Fällen bemähte er sich, und zwar vergeblich, die Bedeutung des Objektes auch in Worten zu demonstrieren.

Recht erhebliche Störungen zeigt auch die Schriftsprache. Ganz besonderes Interesse verdient die Fähigkeit, zu lesen. Die grössten Störungen wies dabei im ganzen seine Fähigkeit, Buchstaben zu lesen, auf. Eine erschöpfende Prüfung liess sich aus äusseren Gründen nicht anstellen. Vom kleinen deutschen gedruckten Alphabet vermochte er flott richtig vorzulesen nur 9 Buchstaben. Als Buchstaben erkannte er offenbar alle, aber auch sonst waren die Abweichungen im ganzen gering. Sie erklärten sich in 12 Fällen aus einer gewissen Unsicherheit im Erwecken des akustischen Lautbildes, die bei ihm als Sachsen, z. B. wie "t" statt d, "p" statt b, "che" statt $\mathrm{g}$ als normal anzusehen, aber auch sonst "twe" statt w, "achiont ein che" statt ch leicht verständlich ist. Zweimal war er durch" das optische Bild irregeführt, "ha" statt v, wobei er letzteres $\mathrm{zu}$ drehen versuchte, einmal „p" statt $q$, vielleicht auch durch die enge Verbindung der Buchstaben im Alphabet, in einem weiteren Falle durch Perseveration, und nur zweimal waren seine Leistungen ganz unsinnige. - Im grossen lateinischen geschriebenen Alphabet war er unsicherer, vor allem machte sich eine momentane Indisposition bemerkbar, nicht weniger als 11 mal benannte er den Buchstaben als "8" oder brachte das Wort 8 in der Antwort vor, übrigens auch, wo er "den Buchstaben 
richtig erkannte, z. B. statt A sagte: "Des ist 8, Meyer 8", oder statt $\mathrm{L}=, 8,8 \mathrm{l}$ hier" usw. Offenbar störte hier das haftende Lautbild, ähnlich wie in noch 2 weiteren Fällen. Fehlerlos reagierte er nur 6 mal, richtig im ganzen $10 \mathrm{mal}$ unter 27 Prüfungen. In 3 Fällen täuschte ihn sicher die Form des Buchstabens, so bei " $\mathrm{E}^{\prime \prime}$ statt $\mathrm{C}$, "T" statt $\mathrm{F}$ und "F" statt T. 4 Reaktionen bei XYZ waren sinnlos. Dreimal versuchte er nachschreibend den Buchstaben zu erkennen, was ihm aber nur einmal gelang.

Immerhin liegt schon hiernach das entscheidende Gewicht offenbar auf der Störung im akustischen Teil des assoziativen Komplexes. Eine wichtige Ergänzung liefert nun sein Verhalten beim Lesen von Worten. Er las solche unter 80 protokollierten Versuchen $56 \mathrm{mal}$ richtig laut vor. Dabei ist $z u$ bemerken, dass er in der letzten Zeit fast ausnahmslos richtig reagierte. Die falschen Antworten häufen sich an einzelnen Punkten zusammen und folgen häufig einem bestimmten für diese Gruppe gleichen Prinzip. Endlich war es ganz gleichgültig, ob man dem Kranken Schreiboder Druckschrift, lateinische oder deutsche Schrift vorlegte.

Man kann die Fehler nun im allgemeinen nicht nur auf die geringere Vertrautheit der ihm vorgelegten Worte zurückführen, da er auch solche, wie Areale, Waldemar u. a. richtig, und die gleichen Worte bald richtig, bald falsch vorlas. In beschränktem Maße traf dies Verhalten indes zu. Es kann ja nach seinen Leistungen beim Buchstabenlesen nicht wunder nehmen, dass er sich durch das optische Bild ihm nicht vertrauter Buchstaben irre leiten und verwirren liess. Dies trifft zu für 10 Fälle und zwar handelte es sich dabei um grosse Buchstaben, hauptsächlich in lateinischer Schreibschrift, bei deutschen nur in der Druckschrift. So las er "Rarbier" statt Barbier, "Eitrone" statt Zitrone, "Icheater" statt Theater, "Figel" statt Igel usf. "Hierfür spricht auch, dass er ein Wort wie Dolch in deutscher Druckschrift richtig las, nicht aber in lateinischer. Andererseits wurde gelegentlich offenbar auch ein falsches Klangbild von an sich richtig aufgefassten optischen Eindrücken ausgelöst, wenn er "Sänge“ statt Säge oder "Vilioline" statt Violine vorlas. Beweisend hierbei scheint besonders, dass er die betreffenden Worte zunächst ganz richtig buchstabierte oder lautierte wie Zunge und dann doch falsch las. Er bediente sich dieses Hilfsmittels im ganzen selten, etwa $5 \mathrm{mal}$, buchstabierte aber dann vollkommen richtig. Vielleicht spielt hierbei auch eine Merkfähigkeitsstörung mit, die sich auch sonst gelegentlich kund gab, wenn er z. B. ein Wort zunächst richtig vorlas, es aber dann bei der Wiederholung verunstaltete.

Ein paar Mal machte er vollkommen sinnlose Fehler. Zu Zeiten, wo er offenbar stark ermüdet war, las er "Komden" statt Klinik, "Besorgenadel" statt Gelegenheit, "Esslich" statt Zeiss usw.; aber auch an diesen Tagen waren seine Leistungen nach einiger Erholung besser. Ganz vereinzelt blieb ein Falschlesen durch Perseveration auf der vorhergehenden richtigen Antwort.

Am bemerkenswertesten ist jedenfalls, dass er auch von den richtig gelesenen Worten, mit Ausnahme seines Namens, keines verstand. Hiervon haben wir nur unter einer ganz bestimmten Bedingung Abweichungen gefunden. Wenn man ihm nämlich unmittelbar neben oder nach dem Wortbilde, welches er richtig vorlas, hierzu gehörige einfache Abbildungen - es befanden sich deren je 6 auf einer Tafel unter einander - vorlegte, so war or häufig imstande, die richtige herauszufinden. Ausnahmslos war 
dieses Verhalten nicht, es gelang ihm bei 2 Prüfungen 10 mal unter 24, bezw. 7 mal unter 15 Fällen, so bei Mühle, Auge, Dolch, Ei, Fisch, Säge, Trommel, Uhr, nachdem er laut und richtig, ausnahmsweise einmal auch, wenn er falsch vorgelesen hatte, wie „Sänge“" statt Säge. Wirkliche Objekte mit den Wortbildern richtig zu identifizieren, gelang ihm dagegen niemals.

Dieser Mangel an Verständnis wurde noch deutlicher, wenn Pat. nicht einzelne Worte las, sondern Sätze. Seine erheblichste Leistung hierin am 17. III. 07 betrifft die Sätze: "Die russische Duma aufgelöst. Nach den letzten Meldungen aus Petersburg war es schon so gut wie sicher zu erwarten, dass die Mehrheit der Duma sich der Forderung - ". "Petersburg, 16. Juni. Durch Ukas an den Senat ordnete der Kaiser die Auflösung der Duma an. Die Neuwahlen sollen ab 14. September stattfinden." Diese Zeitungsnotiz las Pat. vor: „Die russische Duma aufgelöst. Nach den letzten Meldungen aus Petersburg war or schon so gut wie sicher zu erwähnen, dass die Meereihe der Duma der Forderungen - ". "Petersburg den 16. Juni. Durch Ukas an den Senat ordnete der Kaiser Auslösung der Duma an. Neuwahlen sollen 18 Simmer."

Selbstverständlich war dieser Text einem Verständnis nicht gerade günstig. Aber auch bei einfachsten Sätzen versagte dasselbe.

So war er z. B. am 20. VI., wie übrigens bei wiederholter Prüfung stets, absolut unfähig, von verschiedenfarbigen Wollproben die gewünschte zu zeigen, obschon er die Frage: "Wo ist Rot?", "Wo ist Blau?" usw. stets richtig vorlas. Ebensowenig reagierte er auf "schriftliche Aufforderungen: "Zunge zeigen!", oder auf Sätze wie: "Meyer ist krank", „M. ist dumm". "Er fügte dem Satz: "M. ist 3 Jahre "alt" hinzu: "Ja kalt och", wozu er lachte. Es war aber evident, dass er nichts davon verstanden hatte. Er zeigte $z$. B. bei dumm auf die beiden $m$ und sagte: „Ein zwei grün". Nur auf schriftliche Frage: "Wer bin ich", zeigte er "scheinbar Verständnis, sagte "Doktor" und zeigte auf den Arzt. Er hatte aber zuvor vorgelesen: "Wo ist Doktor?" und hatte kein Verständnis gezeigt, obschon wiederholt vom Wort auf den Arzt gezeigt worden war. Offenbar war auch hier die richtige Reaktion nur ein perseveratorisches Zufallsprodukt. Auch an späteren Tagen zeigte er bei zahlreichen Versuchen trotz richtigen Lesens von Fragen, Aufforderungen usw. nur ein einziges Mal ein wirkliches Verständnis. Er ergänzte nämlich in Bezeichnung des vorgelegten Objektes richtig den Satz: "Das ist eine - " mit "Uhr". Endlich las er einmal das Wort "Zuchthaus" als "zu Hause", aber auch hier ist selbst das Verständnis seiner gesprochenen "Worte zweifelhaft.

Nur ganz kurz gedenken möchte ich seiner Fähigkeit, Zahlen zu lesen. Er las ein- und zweistellige richtig vor. Dreistellige traf er nicht stets richtig, z. B. las er .105" statt 605 . Jedenfalls besass er Verständnis für die Bedeutung der Stellenzahl. Auf das Verständnis für den Sinn der Zahlen, der ihm an sich ja bekannt war, ist leider nicht speziell untersucht.

Die spontane Schrift beschränkte sich im wesentlichen auf den Namen des Patienten. Nur gelegentlich schrieb er einmal einzelne andere Worte, z. B. das Wort "Uhr" oder "Fredrstarste" statt Friedrichstrasse, Zahlen wie 107, 1919, 1976, nur einmal, am 2. VII. schrieb er, meist indem er sich dabei ähnliche paraphasische Laute vorsprach, einen längeren unverständlichen Passus nieder, etwa: "Der Bruder ist gut, so sind vorder du vorder voder vom widwden". Die Schrift ist etwas zitterig, die Buch- 
staben gegen Ende nicht mehr exakt, aber doch noch erkennbar in individueller Weise geschrieben.

Im Diktatschreiben wechseln die Leistungen. Auch hier natürlich schrieb er seinen Namen richtig, ebenso zu wiederholten Malen "Leipzig", einmal auch als "Leipziger". Oft schrieb er paragraphisch, wie "Ritter" statt Ring, dann mit Perseveration: "Kutter" statt Uhr. Das Wort Tafel gelang ihm richtig, Tarif als "Larif"; Brot schrieb er "Brott", statt Bett "Bestel" oder „Betig“. Man kann nicht sagen, dass einsilbige Worte gerade bevorzugt gewesen seien, seine Leistungen ähneln aber insofern denen im Nachsprechen, als es niemals gelang, längere als zweisilbige Worte zu erhalten. Alle diese Resultate sind bis in die letzte Zeit unverändert geblieben.

Gutes leistete Pat. im Kopieren, und zwar kopierte er nicht sklavisch, sondern setzte Druckschrift und anch lateinische Schreibschrift in seine deutsche Schreibschrift um. Eigentlich nur an einem der ersten Tage brachte er Fehlresultate wie "Kanan" statt Kanone, dann perseverierend "Mannan" statt Waldemar. Seinen Lesefehlern gleicht "Gigarre" statt Zigarre. Sonst schrieb er einzelne Worte, z. B. Rose, Leipzig, Färberei, Löwe, Riohard, Rom ebeuso richtig ab, wie kurze Sätze, z. B. „das ist eine Uhr" u. dergl. Auch hierin hat sich nichts geändert.

Nur ein einziges Mal hat Pat. spontan, wennschon ungeschickt und zittrig, so doch erkenntlich einen Tisch aufgezeichnet.

Pat. war, wie schon kurz erwähnt, nicht agnostisch. Es ist von keinem einzigen Objekt, welches er sah, jemals beobachtet, dass er dasselbe nicht erkannt hätte. Aber auch bei Wahrnehmung durch Tastsinn oder Gehör liess sich das Gleiche stets feststellen. Die Prüfung war allerdings hier durch den Mangel an Sprachverständnis und Ausdrucksfähigkeit ungemein erschwert. Es liess sich zunächst immer nur feststellen, dass Pat. bei geschlossenen Augen Gegenstände, die man ihn hatte befühlen lassen, wie Fingerhut, eine Klingel, ein Fläschchen, Korke, Stoffproben, Münzen usw., dann bei offenen Augen aus anderen richtig heraussuchte. Das Gleiche bezw. Entsprechende gelang bei akustischer Prüfung nicht stets. Die Fehler entsprangen aber hier meist einer mangelnden Aufmerksamkeitsspannung, die ja dabei in hohem Grade erfordert ist. So wählte er bei einer Prüfung zunächst stets die glänzende Taschenuhr aus den Gegenständen, gleichviel ob man ihm zuvor diese, die Stimmgabel, Schlüsselklirren, Streichholzanzünden usw. zum Anhören gegeben hatte. Nach erneuter Anstachelung and Entfernung der Uhr wählte er aber richtig. Ganz versagte er bei der Aufgabe, das Portemonnaie nach dem Klirren zu erkennen. Unsere Resultate waren sonst bei allen Prüfungen ganz konstante.

Die klare Erkenntnis der Objekte dokumentierte er sonst weiter in der Handhabung derselben. Zeichen einer Apraxie sind weder hierbei noch auch sonst mit ganz verschwindenden und wohl erklärbaren Ausnahmen von ihm dargeboten. Er hantierte mit Bandmaß, Messer, Korkzieher, Schlüsseln, Streichhölzern und anderen Gegenständen vollkommen sachgemäss. Er bediente sich der symbolischen Gestikulation gern und geschickt, um an Stelle der fehlenden Worte einen Ausdruck seines Verständnisses zu geben, z. B. für den Begriff des Rauchens, Sägens usw.

Abgesehen davon war ja durch die Worttaubheit die Prüfung seiner

Deutsche Zeitschrift f. Nerrenheilkunde. 35. Bd. 
Praxie beschränkt auf Beobachtung spontaner und nachgeahmter Handlungen. Die adäquate Wiederholung mimischer und gestischer Aufforderungen ist von mir schon als Beweis des Bestehens einer echten Worttaubheit aufgeführt. Diese erstreckt sich sowohl auf einfache Bewegungen, wie Zunge zeigen, Augen schliessen, Stirn runzeln, Kopfschütteln, Beugen und Strecken der Arme, als auch auf kompliziertere, z. B. in die Hände klatschen, Hände falten, Kreisbewegungen beschreiben. Ebenso wurden Mitteilungsbewegungen, die ihm, wie Gruss-, Kusshandbewegung, eine lange Nase machen, wohl kaum sehr geläufig waren, ganz prompt nachgeahmt, und zwar geschah das ebenso mit der linken wie mit der rechten Hand. Auch in der spontanen Gestikulation, in seinem Benehmen beim Essen, Trinken, beim Sortieren von Wollproben und anderen Tätigkeiten agierte er durchans geschickt. Er reagierte auf ein an die Wand Klopfen hinter seinem Rücken mit der gleichen Handlung, er begleitete vorgepfiffene Melodien mit ausgezeichneten Taktbewegungen usw. Kurz, man kann sagen, dass bei ihm apraktische Erscheinungen nach keiner Richtung hin vorhanden waren.

Eine eingehendere Intelligenzprüfung liess sich bei Pat. natürlich des sprachlichen Verhaltens wegen nicht durchführen. Gleichwohl liessen sich aus seinem Verhalten, auch abgesehen von dem schon Angeführten, Rückschlüsse darauf sehr wohl ziehen. Er zeigte Interesse und Verständnis für seine Umgebung, hatte offenbar dem Benehmen nach ein ziemlich gutes Urteil für die Schwere der Krankheit auch bei anderen seiner Mitpatienten, sowie für deren Verhalten ihm gegenüber. Auch für Gegenstände, die seinem Berufe nahe lagen, Möbel u. dgl., bekundete er deutliches Interesse. Stets höflich und zuvorkommend, ging er verständnisvoll auf die Untersuchungen ein, stellte selbst zu denselben Tisch und Stühle im Zimmer zurecht, merkte auf alles, was dabei vorging, korrigierte, wenn das Tintenfass zufällig in bedrohliche Lage geriet, zupfte einen Wattebausch rom Ärmel des Arztes und suchte sich sonst nützlich zu machen. Bei einer besonders ausgedehnten Exploration verfolgte er wohl gelegentlich die Zahl der Protokollseiten mit einem nicht sonderlich erfreuten: „Immer noch mehr?" Auf der Abteilung fand er sich räumlich und bezüglich der Anstaltsordnung sehr gut zurecht. Nur in einem anfänglich in der Nacht vom 8.-9. VI. auftretenden Verwirrtheitszustand ist bemerkt, dass er oft aufstand, nach der Tür lief, offenbar ohne zu wissen, wo er sich befand, und dass er fremde Kleidungsstücke anzuziehen versuchte. Leider ist versäumt, seine Rechenfähigkeit zu prüfen, was mit schriftlichen Aufgaben sicher möglich gewesen wäre. Bemerlst ist gelegentlich, dass er sich auch bei kleineren Personenzahlen verzählte. Seine spontan ablaufende Vorstellungstätigkeit entzog sich leider einer genaueren Untersuchung. Jedenfalls füllten der Krankheitszustand und der Wunsch, bald nach Hause zu kommen, den grössten Teil seines geistigen Horizonts aus. Die Stimmung war im ganzen eine ruhige, doch sind wiederholt bei ihm, so schon im Beginn, in der Zeit vom 6.-8. VI., ebenso längere Zeit hindurch vom 22.- 30. VI. im Anschluss an eine Verschlechterung des körperlichen Zustandes und endlich zum Schluss der Behandlung erregtere Zeiten vorgekommen. Er war weinerlich, verstimmt, jammerte und klagte viel, sobald er mit anderen zusammenkam; auch wenn man inn nicht ansprach, verfiel er in eine extreme Logorrhoe. Er war dann schwer zu konzen- 
trieren, liess sich nur mit Widerstreben körperlich untersuchen und ging auf Explorationen nicht ein. Immer aber auch in dieser Zeit hatte er kurze Zeiträume, Stunden, in denen man sich einigermassen mit ihm verständigen konnte und in denen das sprachliche Bild unverändert zutage trat. Gerade in dieser Zeit, am 29. VI., gab er ein besonders gutes Zeichen seiner Leistungsfähigkeit, indem er die ihm vorgelegte Rentenquittung ohne weiteres erkannte und glatt und richtig vollzog.

Nur bezâglich des körperlichen Zustandes habe ich nachzutragen, dass Pat. am 22. VI. plötzlich unter den Zeichen einer Herzinsuffizienz erkrankte. Das Herz war deutlich nach links, kaum erheblich nach rechts verbreitert. Es trat ein lautes systolisches Geräusch auf, der Puls war klein und betrug 130 p. Min. Am 23. VI. traten Rasselgeräusche über beiden, hauptsächlich dem rechten Unterlappen auf und Pat. entleerte ein klumpiges, rein blutiges Sputum. Die Herztätigkeit besserte sich aber allmählich wieder und die Zeichen des Lungeninfarktes gingen zurück, so dass Pat. am 9. VII: ohne Nachteil in der medizinischen Gesellschaft vorgestellt werden konnte.

Erst am 14. VII. traten dann neuerdings bedenkliche Erscheinungen auf, Blässe und Cyanose, Steigerung der Pulsfrequenz über 120 pro Min., dann auch Rasseln und Knarren uber dem linken Unterlappen, eine allmählich ansteigende Dämpfung mit Abschwächung der Atmung und des Stimmfremitus. Es traten pneumonische Erscheinungen hinzu und am 16. VII. erfolgte der Exitus letalis.

Bei der Autopsie mussten wir uns aus äusseren Gründen auf die Kopfsektion beschränken, von der ich hier nur die besonders interessanten Daten hervorheben will. Das Gehirn war nicht nennenswert atrophisch (Gehirngewicht frisch $1270 \mathrm{~g}$ ), wies aber schon äusserlich 4 Erweichungsherde auf.

In der linken Hemisphäre (Fig. 1) findet sich ein solcher von $6,5 \mathrm{~cm}$ Länge. Derselbe umfasst den hinteren Teil, etwa $1 / 3$ der 2. Temporalwindung, nach hinten bis an den Gyrus angularis heranreichend. Nach vorn zu lässt er die untere Partie der 2. Temporalwindung und die 3. Temporalwindung überhaupt intakt, greift aber in den mittleren Teil der 1. Temporalwindung über und zwar gerade an der Stelle, wo die Querwindung die Aussenfläche des Schläfenlappens erreicht. Diese Querwindung ist in ihrer äusseren Hälfte innerhalb der Fossa Sylvii sehr schmal und atrophisch, die innere Partie, die Wurzel, dagegen scheint makroskopisch erhalten. Der Herd ist im hinteren Abschnitt in der 2. Schläfenwindung sehr weich und von cystöser Beschaffenheit.

Ein zweiter Herd, oberflächlich, von etwa $2 \mathrm{~cm}$ Länge und $1 / 2 \mathrm{~cm}$ Breite, liegt im oberen vorderen Abschnitt des Gyrus angularis, gerade am Übergang in den Gyrus supramarginalis. Letzterer selbst ist sonst überall, zumal am Übergang in die 1. Temporalwindung, unversehrt.

Ein dritter Herd, nach seiner Beschaffenheit älteren Datums, sitzt in der 3. Frontalwindung. Er lässt allerdings den Fuss derselben völlig intakt, ergreift aber den vorderen Abschnitt der Pars triangularis und den davor zur Basis des Stirnlappens überleitenden Windungsteil; nach vorn oben reicht er mit einem Zipfel in die 2. Frontalwindung, etwa in deren Mitte hinein. Hier ist er ziemlich tief eingesunken, während der untere 
Teil des Herdes oberflächlich zu sein scheint. Die oberflächliche Ausdehnung dieses Herdes beträgt etwa $2,5 \times 3 \mathrm{~cm}$.

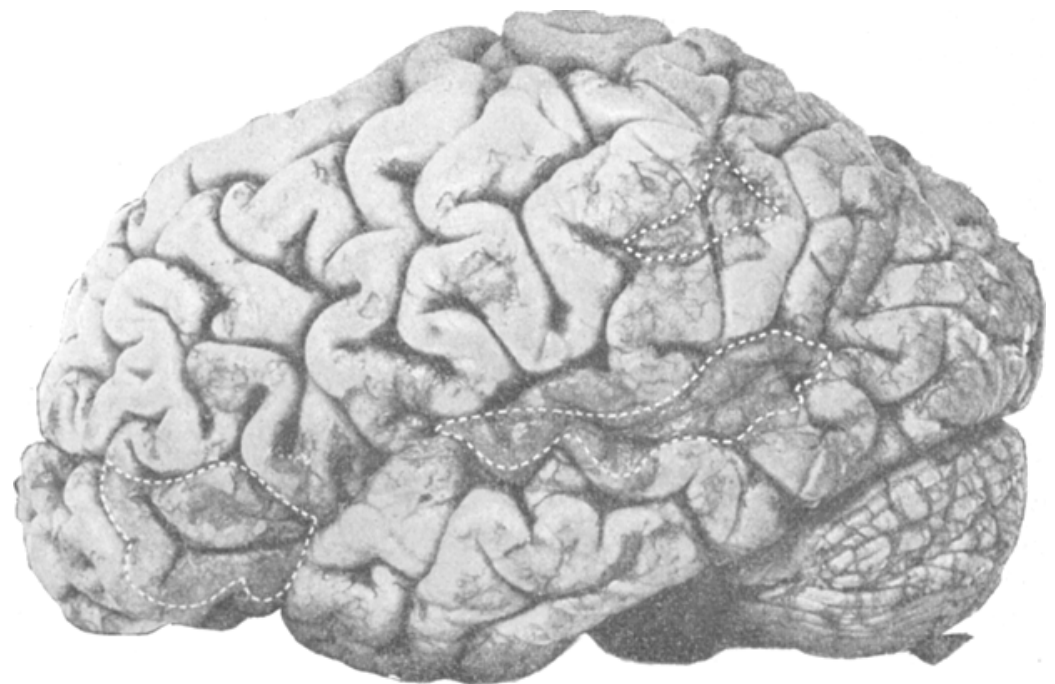

Fig. 1. Linke Hemisphäre.

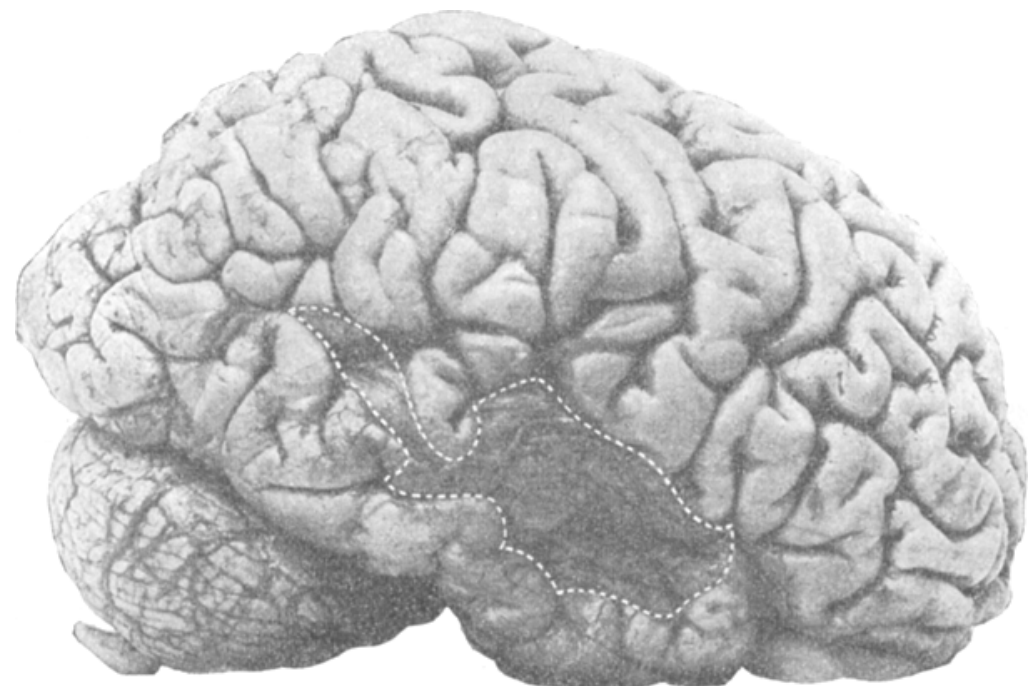

Fig. 2. Rechte Hemisphäre.

Eine besondere Überraschung bot uns, dass auch die rechte Hemisphäre einen grossen Erweichungsherd und zwar im Schläfenlappen aufwies (Fig. 2). Mit Ausnahme der vordersten Spitze erweicht sind 
reichlich die vorderen $2 / 3$ der 1 . und 2. Schläfenwindung und in einen schlaffen Sack verwandelt. Von der 2. Temporalwindung ist das hintere Drittel erhalten. Von der 1. Temporalwindung intakt ist nur der hinterste, in den ūbrigens völlig unversehrten Gyrus supramarginalis übergehende Abschnitt. Hinter diesem erstreckt sich der Herd als ein schmaler, tief eingesunkener Spalt hinein in den vorderen unteren Teil des Gyrus angularis in einer Gesamtlänge von $2 \mathrm{~cm}$. Die Länge des Herdes im Schläfelappen beträgt 5,5-6,0, die grösste Breite 2,5 cm. Beim Aufheben des Opereulum schliesslich zeigt sich, dass die temporale Querwindung in der Fossa Sylvii im wesentlichen erhalten geblieben ist und zwar in Verbindung mit dem Gyrus supramarginalis.

Mit diesem makroskopischen Befunde haben wir uns vorlänfig begnügt und das Gehirn in toto zur mikroskopischen Untersuchung auf Serienschnitten eingelegt.

Auf den allgemeinen Verlauf der Krankheit einzugehen, obwohl derselbe manches Interessante bietet, erübrigt sich hier. Es kann ja kaum bezweifelt werden, dass es sich um einen embolischen Prozess auf Grundlage einer Herzaffektion handelt. Wir hören nun beim Pat. von 2 apoplektiformen Attacken, deren eine vor $1 \frac{1}{2}$ Jahren sich abgespielt hat. Ich trage keine Bedenken, auf diese den frontalen Herd in der linken Hemisphäre zu beziehen, der vorübergehende Aphasie als Fernwirkung erzeugte. Wahrscheinlich ist aber damals auch schon der alte Herd im rechten Schläfenlappen entstanden, der ausser vielleicht vorïbergehenden Lähmungserscheinungen (?) symptomlos geblieben ist. Unbestreitbar ist sicher das letzte Krankheitsbild die Folge des linksseitigen Schläfenlappenherdes.

Bevor ich auf eine Würdigung des Falles eingehe, gebe ich noch zum Vergleich zwei weitere Fälle meiner eigenen Beobachtung. Da dieselben nicht zur Autopsie gekommen sind, will ich sie nur ganz kursorisch ausführen.

Fall 2. Georg S., 55 jähriger Tabaksarbeiter, aufgenommen 12. IV. 1906.

Pat. ist am 9. IV, 1906 abends erkrankt, legte plötzlich seine Zeitung hin, er könne nicht mehr lesen, begann verkehrt zu sprechen, so dass man ihn nicht verstehen konnte, verstand nicht mehr, was man zu ihm sagte.

Die somatische Untersuchung ergab am 12. IV. deutliche Arteriosklerose, Pupillendifferenz r. $>$ l, rechtsseitige Mundfacialisparese, Achillessehnenreflex rechts stärker als links.

Motilität, Reflexe, Sensibilität für Berührung und Schmerzreize ungestört. Gesichtsfeld bei wiederholter Prüfung beiderseits obne Defekte, Hörfähigkeit vollkommen ausreichend, Ohrenspiegelbefund normal.

Pat. ist bei der Aufnahme fast absolut worttaub, reagiert auf keine Frage: Wie heissen Sie?, Aufforderung: Zeigen Sie die Zunge! Augen zu!, auf Beleidigungen: Sie sind ein Lump! Sie haben gestoblen! nicht einmal auf seinen eigenen Namen. Er vermag kein Wort nachzusprechen. Die spontane Sprache besteht aus abgerissenen Satzteilen ohne alle kon- 
kreten oder Hauptworte: „Ja das wird nicht mehr eben - ich denke, dass er morgen fortgeht - mir ist eben - da kann eben - wie gesagt." Er liest kein Wort, malt aber in ungeschickter Weise einige Züge und Buchstaben nach, schreibt anch spontan seinen Namen.

Beim Gebrauch von Gegenständen, die er offenbar erkennt, benimmt er sich nicht ungeschickt, wohl aber beim Nachahmen von Bewegungen, wozu er nur schwer zu bringen ist.

Das Krankheitsbild blieb aber auf diesem Standpunkte nicht lange stehen. Schon am 13. IV. vermag er einzelne Buchstaben, auch Worte, letztere allerdings unvollkommen (Adler $=A$-d-ler, Adeler, Bier $=$ Lier) zu lesen. Kopiert Buchstaben und Worte richtig und schreibt wieder den Namen, wie Geburtstag und Jahr.

Am 15. IV. beginnt er einzelne mündliche Aufforderungen zu verstehen: Zeigen Sie die Zunge! usw., andere nicht. Heben Sie den rechten Arm hoch! Zeigt die Zunge. Von Gegenständen wählte er bei Namensnennung sehr oft die richtigen aus (Uhr, Portemonnaie, Schlüssel, Streichhölzer usw.) und spricht auch die Namen nach. Die spontane Sprache ist wenig gebessert, die Namen von Objekten findet er nicht, sondern umschreibt sie. Er liest eine ganze Reihe von Worten, auch schwierige, richtig vor (Gardinenausstellung, Hermann Gerson, Werther-Strasse 9-12 usw.). Zum Diktatschreiben bringt man ihn nicht, doch kopiert er Worte richtig. - Wiederum fällt eine Ungeschicklichkeit beim Nachahmen ron Bewegungen auf.

In der Folge ist bemerkenswert, dass Pat. häufig Worte und Fragen nicht gleich versteht, sondern sie zunächst fragend nachspricht, um sie dann, aber auch, nicht immer, erst zu verstehen.

Als Resumé einer eingehenden Prüfung vom 18. IV. ergeben sich erhebliche Fortschritte.

Das Wort- und Sprachverständnis hat sich so weit gebessert, dass Pat. zahlreiche Fragen und Aufforderungen gut beantwortet. Wie alt sind Sie? - "Wie alt, nu ich bin 56." Wieviel Kinder haben Sie? "Wieviel Kinder, nu mein Junge, nu die 2, die stehen doch hier, die 2." "Wer bin ich? "Ach wer Sie sind, Sie sind der Herr Dr. usw." Sind Sie krank? Wo wohnen Sie? usw. usw. Manche komplizierteren Sätze: Stehen Sie auf und offnen Sie das Fenster! versteht er allerdings nicht. Gegenstände wählt er fast stets richtig aus bei Nennung (Löschblatt, ZentimetermaB), selten fällt einer aus, z. B. Kork.

Ein- und zweisilbige Worte spricht er fast stets fliessend nach, seltener auch drei- und viersilbige.

Die Spontansprache ist noch immer sehr wortarm und stockend. Gegenstände bezeichnet er nur ganz ausnahmsweise richtig, z. B. Dreimarkstück; meist ziemlich sinnlos, z. B. Portemonnaie $=$ „Des Dings, na wir wissen ja, die Dinger hier". - Die Zahlenreihe sagt er bis 20 glatt her, Alphabet und Monatsnamen recht mangelhaft, aber doch frei lautierend und artikulierend.

Grosse und kleine Buchstaben liest er mit nur wenigen Fehlern (C, Q, Y - c, e, l, q, s, t, y) richtig vor, Worte und kurze Sätze glatt aus Schreib- und Druckschrift.

Er kopiert solche fehlerlos, die Diktatschrift ist sehr mangelhaft 
(Tabak $=$ "Dabak", August $=$ "Achust", Schubmacher $=$ "Schuwarer", Nervenklinik $=~ " n e r v i e l$ klenig“). Spontan schreibt er nur "seinen Namen.

Bis zu seiner Entlassung am 30 . IV. hat sich das Wortverständnis gehoben, blieb aber doch zusammenhängenden Sätzen gegenüber, wie: Fassen Sie einmal mit der rechten Hand an die Nase! Legen Sie sich Ihr Kopfkissen auf die Füsse! usw. unvollkommen.

Im Nachsprechen versagte er nur noch bei schwierigen mehrsilbigen Worten. Die Spontansprache blieb wortarm und leicht paraphasisch, das Bezeichnen von Gegenständen gelang ihm für gebräuchliche Objekte gut, oft versagte er freilich, wie bei Streichholzschachtel, oder gebrauchte paraphasische Bildungen (Knopf $=$ "Knöcke", Vorhang = "Gantine").

Er las lange Sätze laut richtig vor, nur schwierige Worte, wie Zentraltheater, zoologischer Garten, kamen paraphasisch. Mangelhaft blieb das Verständnis des Gelesenen, das offenbar oft nur dem Auffassen einzelner Worte zu verdanken war. Den Satz: „S. ist 6 Jahre alt und 5 Meter hoch" z. B., beantwortete er mit: „5 Meter, na so alt war ich nicht" usw.

Er kopierte lange Absätze richtig, schrieb auch auf Diktat Worte und einzelne kurze Sätze, dagegen liess er sich zum Spontanschreiben nicht bewegen.

Eine Nachuntersuchung am 8. VI. 1906 hat schliesslich ergeben, dass trotz gewisser Fortschritte, zumal in der Ausdrucksfähigkeit, doch in allen aufgeführten Punkten, auch im Sprachverstänđnis, noch erkennbare Defekte bestanden.

Fall 3. Emilie R., 58jährige Maurersehefrau, aufgenommen am 18. III. 1906.

Früher gesund, hatte Pat. am 15. I. kaltes Gefühl am rechten Arm und Bein, am 23. I. 1906 fiel sie plötzlich um, war bewusstlos, tags darauf vorübergehend rechts gelähmt. Besserung bis auf ganz leichte rechtsseitige Schwäche, soll zeitweise "irre" geredet, Personen verwechselt haben. Seit 8 Tagen im Anschluss an einen entzündeten Varixknoten am Bein Taedium vitae der Schmerzen wegen. Seither soll sie zeitweise Gesprochenes nicht verstehen und unverständlich sprechen.

Die somatische Untersuchung ergibt ein von dem Varix ausgehendes ausgedẹntes akutes Ekzem. Pat. macht einen ziemlich senilen Eindruck, es besteht eine erhebliche Arteriosklerose. Puls 106 p. M., regelmässig. Abdominalorgane o. B.

Pupillen l. $>$ r. Lichtreaktion wenig ausgiebig, aber prompt. Rechtsseitige Parese im Mundfacialisgebiet, Zunge wird etwas nach r. vorgestreckt. R. Arm und rechtes Bein sind deutlich paretisch, zeigen leichte Spasmen und eine deutliche Atrophie gegenüber den linken Extremitäten. (Der Umfang der Extremitäten differiert um mehrere Zentimeter.)

Sämtliche Sehnenreflexe sind gesteigert. Pat.-Refl. rechts $>$ links, Patellarclonus. Achillessehnenreflex rechts zur Zeit nicht auszulösen. Rechts ausgesprochener Babinski.

Sensibilität für Berührungen und Nadelstiche zeigt keine merkliche Differenz. Beim Betasten von Gegenständien ist Pat, rechts ungeschickter als links, erkennt solche aber beiderseits. Sie hat im Erkennen derselben 
auch beim Sehen und vom Hören, um das vorweg zu nehmen, nie Störungen gezeigt.

Eine exakte perimetrische Gesichtsfeldaufnahme war nicht möglich, bei einer Untersuchung mit Licht am Perimeter liess sich ein klar ausgesprochener Gesichtsfelddefekt nicht erkennen.

Sie hörte gut, Uhrticken, hohe und tiefe Töne (Stimmgabel, Pfeifen), Flüsterstimme auf beiden Ohren in ca. $20 \mathrm{~cm}$. Der Ohrenspiegelbefund ergab Trübung und Einziehung beider Trommelfelle, sonst aber keine Veränderung. - Trotz des relativ guten Gehörs fiel nun auf, wie unaufmerksam Pat. auch auf laute Geräusche, Händeklatschen, Klingeln, auch Läuten eines Weckers in ihrer nächsten Nähe war.

Bezüglich der Sprache will ich, da die vorhandene Aphasie eine unvollkommene war und in ihrem Verlauf auch unregelmässige Schwankungen aufwies, nur die an dieser Stelle wesentlichen Daten wiedergeben. Bei sehr eingehenden Untersuchungen in den ersten Tagen, vom 18.-22. III. 1906, ergab sich zunächst, dass Pat. in ihrem Sprachverständnis erheblich beschränkt ist. Aufgehoben ist dasselbe nicht, aber doch so beeinträchtigt, dass eine zusammenhängende oder auch nur einige Zeit dauernde Verständigung mittels der Lautsprache ausgeschlossen war. Sie beantwortete wohl einzelne Fragen: "Wie heissen Sie? Wie alt sind Sie? Wo wohnen Sie?", kam, soweit sie nicht durch ihre noch zu erwähnende Apraxie darin behindert war, Aufforderungen nach (Zunge, Zähne zeigen! Augen zu! Geben Sie mir die rechte Hand!). Sie suchte endlich auf Namensnennung Gegenstände unter den ihr vorgelegten heraus (Uhr, Ring, Licht). Sehr oft aber und zwar in der Mehrzahl der Fälle versagte sie diesen Aufgaben gegenüber und zwar oft auch bei der gleichen Anrede, den gleichen Bewegungen und Objekten gegenüber. Sie sagte z. B. auf die aúfmerksam angehörte Frage: Wie alt sind Sie? "Emilie Riedrich heisse ich", oder wer bin ich denn? "Ja, wie heisst denn "gleich alles?, die Uhr". Sie reagierte nicht auf die Aufforderung, die Zunge zu zeigen, an die Nase zu fassen, an das rechte Ohr usw. Sie fand Schlüssel, Uhr oder Portemonnaie unter vorgelegten Objekten nicht heraus. Ihre Leistungen waren besser, wenn sie in ruhiger Gemütsverfassung und wenn sie ausgeruht war, aber auch dann kamen reichlich Fehlresultate vor.

Sie verstand die Worte auch dann oft nicht, wenn sie dieselben, was häufig der Fall war, richtig wiederholte, z. B. geben Sie mir den Schlüssel: "Schlüssel", griff aber dann nach dem Portemonnaie, oder fassen Sie an Ihre Nase: "Nase", kam dem aber nicht nach. In einer Reihe von Fällen führte sie das Nachsprechen allerdings zum Verständnis. Dabei hatte sie beim Nachsprechen mehr als zweisilbiger Worte sichtliche Schwierigkeiten, sprach stark paraphasisch, z. T. auch ganz andere Worte, oft gelangen ihr auch kürzere Worte nicht.

Auffallend und wichtig war nun aber, dass bei ihr die Verständigung auf schriftlichem Wege zwar nicht vollkommen, aber doch in weit besserer Weise möglich war. Die Prüfung ergab, dass Pat. einzelne Buchstaben z. T. richtig las; manche ergänzte sie zu Worten, andere fielen ganz aus. Worte las sie meist vollkommen richtig vor, ebenso kürzere Sätze. Wenn nun Pat. eine mündliche Aufforderung nicht befolgte, selbst wenn sie die Hauptworte derselben nachgesprochen hatte, so gelang es in zahlreichen Fällen, sie auf schriftlichem Wege zur richtigen Reaktion zu bringen, z. B. 
blieb die Antwort aus auf die mündliche Frage: "Wo sind Sie geboren"? Auf die schriftliche folgte: "In Eilenburg bin ich geboren". Ebenso auf die Frage: "Wieviel Kinder haben Sie?" Sie zeigte Bettdecke, Zimmerdecke, den vor ihr liegenden Schlüssel erst, als man sie schriftlich befragte usw. Dies Verhalten ist zahlreiche Male konstatiert worden. Absolut erfolgreich war dies Aushilfsmittel nicht, es kam vor, dass Pat. Aufforderungen und Sätze verkehrt vorlas and dann nicht verstand; mehrfach las sie auch richtig vor, verstand aber dennoch den Sinn nicht, gelegentlich selbst (NB. wie auch beim Hören) von Sätzen wie "Sie haben ge. stohlen" u. dergl., oder merkte nicht, dass überhaupt für sie eine Frage oder Aufforderung vorlag.

Die spontane Sprache zeigt echt sensorisch-aphasischen Charakter, es fehlen die jedesmal von ihr benötigten Hauptworte, sie produziert viele bedeutungslose Sätze, bringt Paraphasien, wiederholt sich oft in Worten, Wendungen und Gedankengängen: „Es ist alles genellt, bitte, bitte mein Herr, lassen Sie doch meinen Mann kommen. Ich hab schon alles genäht, es ist ja richtig, bitte, bitte mein Herr, die sind ja zufrieden. Ich muss ja länger dabei sind, wir haben ja grosse Wohnung, meine Schwester, meine Kinder, Ewald mein Sohn" usw. Die amnestische Störung war sehr ausgesprochen beim Bezeichnen von Gegenständen. Höchstens in einem Viertel der Fälle gelang es ihr, den richtigen Namen herauszubringen, oft erst nach wiederholten Bemühungen, während sie für gewöhnlich den Gebrauch usw. umschrieb oder paraphasische Bildungen produzierte, z. B. Bleistift $=$ "Das hier, womit man schreibt", Portemonnaie $==$, Und hier ist man alles rein tan" usw.

Spontan schrieb sie ihren Namen und einige andere Namen aus ihrer Farnilie, sonst nur wenige, oft entstellte Worte, z. B.: "Mein Brieder geiht es bald gros - "; "Meine Schwetter gehen." - Auch auf Diktat schreibt sie paragraphisch, z. B.: "Absel Bann" = Apfelbaum. Ihre Schrift ist zitterig und etwas ausfahrend, stellenweise geradezu leicht ataktisch. Beim Kopieren von Druckschrift transponiert sie meist in Kurrentschrift, bildet aber bisweilen einzelne Züge sklavisch nach. Schreibschrift schreibt sie meist richtig ab. Sehr ungeschickt erwies sie sich beim Kopieren von einfachen Strichzeichnungen.

Die weitere Beobachtung ergab nun bei unserer Kranken eine, wenn auch mit einigen Schwankungen fortschreitende Besserung. Völlig neue Erscheinungen traten nicht auf, die schon erwähnten verschwanden nicht vollkommen, nahmen aber an Intensität ab. Das gilt zunächst einmal für die Zeit vom 23. bis Endè März 1906.

Es besserte sich das Sprachverständnis. Freilich blieb sie noch bis zuletzt beschränkt in der Fähigkeit, ganze Sätze zu verstehen, erriet aber, da sie einzelne Worte auffasste, nicht selten den Sinn. Bisweilen versagte sie allerdings auch bei kurzen Sätzen wie: "Haben Sie Schmerzen?" oder "Heut bekommen Sie Besuch". Auch dann wieder war evident, dass sie schriftliche Mitteilungen besser auffasste. Die Leistungen im Lesen sind ebenfalls, wenigstens quantitativ, etwas gebessert. Im Nachsprechen zeigte sie keine Schwierigkeiten mehr. Worte, wie Nervenklinik, Glockenläuten, Sellerhausen, Elektrizität, brachte sie ganz richtig zustande, nur bei Berufsgenossenschaft und Konstantinopel stolperte sie.

Grossen Wert haben wir in dieser Zeit auf die Prüfung ihres Gehörs 
gelegt und sind dabei zu dem schon angeführten Resultat gekommen. Wir haben ihr auch Melodien vorgefuhrt, gesungen, gepfiffen, auf einer Spieluhr usw. Dabei stellte sich heraus, dass sie diese sehr gut erkannte, auch und zwar teilweise mit dem Anfang. des Textes nachzusingen vermochte. Von selbst zu singen liess sie sich nicht bewegen.

Die Spontansprache ist reichhaltiger und geordneter geworden, aber noch immer wortarm, z. B. erzählt sie von ihrem Bein: "Ein bischen Laufen und überhaupt, dass das Gelumpe besser wird. Des war eher rein tot alles, keinen Schritt konnte ich laufen, war ich gestürzt und haben sie mich müssen raufschleppen" usw. - - - "essen kann ich mit der Hand wieder, blos so rum kann ich nicht um "den Kopf, das ist alles wieder wie tot. Hier ist nichts mit der Klinik, dem Arm." - Bei Reihenaufzählungen brachte Pat. ganz gut die Zahlen, Wochentage und Monate. Ausführliche Prüfungen der Fähigkeit, Objekte zu benennen, ergaben die gleichen amnestischen Störungen, Paraphasien, Umschreibungen, nur selten richtige Bezeichnungen. Die Leistungen liessen keinen deatlichen Unterschied erkennen, ob sie nun die Gegenstände nur sah oder hörte, tastete, roch oder schmeckte, z. B. äusserte sie sich zum Uhrticken, das sie hörte, erst: "Die höre ich sehr gut die Uhr", dann in einiger Entfernung: "Jetzt riechts ja nicht mehr viel dran", und auf der anderen Seite: "An mein Ohr, an meine Kirche, da riecht sie doch an meine Nase, da höre ich sie riechen". Kaffee erkannte und benannte sie nach dem Geruch, für Petroleum galt nur ersteres: "Das ist, als wenn man so wollte Flecke machen lassen, was habe ich für Flecke gemacht zu Hause". Relativ am häufigsten gelang ihr Benennung getasteter Gegenstände (Ring, Knopf, Taler), aber keineswegs immer, denn die Worte Schlüssel, Pinsel, Portemonnaie fand sie dabei so wenig wie bei Ansehen. Bestenfalls beantwortete sie $1 / 2-1 / 3$ der Fragen richtig, meist und im Durchschnitt sehr viel weniger, etwa $1 / 6$.

Ihre Schreibleistungen blieben etwa die gleichen.

Sehr deutlich zeigte sich das Bestehen einer gewissen Apraxie. Schon zuvor war gelegentlich beobachtet, dass sie mit Gegenständen oft nicht geschickt hantierte, sich z. B. beim öffnen eines Portemonnaies sehr schwerfällig benahm, dass sie ein ihr vorgehaltenes Streichbolz nicht ausblies usw. Sie kam aber schliesslich mit solchen Handlungen immer noch zu Ende, auch mit Streichholzanzünden usw. - Sie hatte nun auch Schwierigkeiten, Bewegungen, die man von ihr forderte auszuführen, auch vorgemachte nachzuahmen. Offenbar verstand sie diese (nicht verbale) Aufforderung schwerer. Nur mit Mühe brachte sie solche wie Etschbewegung fertig, gar nicht, auch trotz passiver Ausführung, das Zusammenführen der Finger bei Ataxieprüfung. Händeklatschen, Händefalten nnd Umeinanderwirbeln gelangen sofort und glatt nach einmaliger Ausführung. Mundöffnen erfolgte prompt, Zähne- und Zungezeigen nicht zu allen Zeiten. Aufblasen der Backen brachte sie auf keine Weise zustande, statt zu pusten, atmete sie nur tief.

Es lässt sich schliesslich eine dritte Periode abgrenzen, die den April bis zur Entlassung der Kranken umfasst. In diese Zeit fällt eine vorübergehende Verschlechterung, 11.-13. IV.: Auftreten von Parästhesien und Taubheitsgefühl im rechten Unterschenkel, stärkere Bewegungsbeschränkung und deutlichere Paresen in der rechten Seite, Wiederkehr des zeitweilig nicht nachweisbaren Babinskischen Phänomens. - Bezüglich der Sprache 
lässt sich eine sehr wesentliche Besserung des Wortverständnisses nicht nachweisen. Für einzelne Worte bestehen nur noch geringe Ausfälle, Sätze versteht sie dagegen auch bei einfacher Fassung (Wie fühlen Sie sich? War ihr Mann hier? usw.) nur in etwa einem Drittel der Fälle. Nachsprechen zeigt nur bei schwierigen drei- und mehrsilbigen Worten Störung. Spontansprache wenig verändert, recht gute Leistungen im Reihenaufsagen. Bezeichnung bekannter Gegenstände oder von Abbildungen ergab richtige Resultate bis zur Hälfte der Aufgaben. Ausgesprochen waren ihre Fortschritte am meisten in der Schriftsprache. Sie las fast sämtliche Buchstaben mit Ausnahme der selteneren richtig vor, im Durchschnitt zwei Drittel der Aufgaben. Worte, auch Sätze las sie mit seltenen Ausnahmen, infolge Verlesens einzelner Worte, richtig vor, verstand auch fast stets den Sinn. Nur bei sinnlosen Sätzen, wie "Frau R. heisst Otto und ist 7 Jahre alt", versagte sie und suchte einen anderen Sinn hineinzulegen, andere dergleichen dagegen, z. B. "die Katze ist ein Vogel" oder "5 $\times 5=600$ " in Worten, lehnte sie bestimmt ab. - Kopieren, auch von kurzen Sätzen, gelang gut aus jeder ihr bekannten Schriftart und zwar transponierend. Auf Diktat schrieb sie leicht paraphasisch, z. B.: "Lieber Mann besuche mich am sunsten Tag" (am Sonntag). Sie versuchte spontan Briefe zu schreiben, was allerdings stark paraphasisch ausfiel. "Mein lieber Vater Schrab mir lieber, wil es bies gut, allen ist wie gieht es " usw.

Bei einer Vorstellung der Pat. im Juli 1906 schliesslich konnte ein sehr deutlicher Fortschritt in jeder Hinsicht konstatiert werden, ohne dass aber die Worttaubheit völlig verschwunden war. Im Vordergrunde stand jetzt die amnestisch-paraphasische Störung der Sprache, am stärksten gebessert war die spontane Schrift, was folgende Stelle eines selbständig geschriebenen Briefes belegen mag: "Wenn ich nicht schlafen kann, bin ich zu Müde. Ach mein schwären Kopf wird nicht so sprägen mehr, am Sontage war zu schlägt" usw.

Seither habe ich über das Ergehen der Pat. keine Nachricht wieder erhalten.

Von den vorstehenden Fällen von Worttaubheit zeigte der erste und zwar dauernd einen nahezu völligen Verlust des Wortsinnverständnisses; Wortlautverständnis und Nachsprechen waren dagegen bis zu erheblichem Grade erhalten. Es bestand die Fähigkeit, laut zu lesen, aber ohne Verständnis für den Sinn des Gelesenen, Fähigkeit zu kopieren, bis zu einem gewissen Grade auch auf Diktat zu schreiben, dabei amnestisch-paraphasische Störung der spontanen Sprache und hochgradige Störung der Spontanschrift. Wir haben es also klinisch zu tun mit einer Symptomgruppierung, die dem Bilde der von Wernicke schematisch postulierten Form der transcortikalen sensorischen Aphasie nahe entspricht und zwar auf Grund eines, wie die Sektion ausweist, doppelseitigen Schläfenlappenherdes.

Gerade wenn man nun versucht, die Erscheinungen eines Krankheitsfalles mit dem Ergebnis der Autopsie in Einklang zu bringen, sieht man besonders deutlich die Unzulänglichkeit der schematischen Vorstellungen. Natürlich lassen sich nicht auf Grund einzelner Fälle all- 
gemein gültige Anschauungen über Wesen und Entstehung der Aphasieformen gewinnen. Dazu bedarf es bei den hier vorhandenen zahlreichen Schwankungen und Variationen eines Querschnittes, gewonnen aus der Vergleichung möglichst zahlreicher und möglichst exakter Beobachtungen. - Ich gebe hier in Kürze, was ich bei meiner Zusammenstellung an Resultaten über die Art und Gesetzmässigkeit der einzelnen Erscheinungen, über die Zusammengehörigkeit derselben und ihre Abhängigkeit von bestimmten anatomischen Veränderungen habe ermitteln können.

Man kann zunächst, ausgehend von dem für unsere Betrachtung wesentlichen und grundlegenden Symptom der Worttaubheit, rein klinisch unterscheiden zwischen Fällen totaler und solchen partieller Worttaubheit. Ich gehe hier nicht ein auf die bei diesem Begriff zunächst vorausgesetzte Bedingung, dass ein ausreichendes Hörvermögen vorhanden ist, dass sich kein peripher oder infracortikal bedingter Ausfall speziell der sogen. Sprachsexte findet. Diese Voraussetzung wird ja erfahrungsgemäss wieder eingeschränkt dadurch, dass in dem Bilde der Rindentaubheit doch gleichzeitig eine Worttaubheit bestehen und symptomatologisch charakterisiert sein kann, sowie dass neben der Worttaubheit auch periphere Hörstörungen bestehen können. Bei der totalen Worttaubheit fehlt sowohl Wortlaut- als auch Wortsinnverständnis. Die partielle Worttaubheit lässt sich gliedern 1. in eine Form, bei der nur das Wortsinnverständnis verloren, das Wortlautverständnis aber erhalten ist, eine Störung, die sich auf alle Worte beziehen kann, 2. in eine Form, bei der sowohl Wortlaut- als auch Wortsinnverständnis partiell verloren gegangen sind.

Es gibt in der Literatur eine Anzahl von Fällen, in welchen die Kranken in der Tat bei ausreichendem Hörvermögen nicht ein einziges Wort als solches aufzufassen vermochten. Ein Kranker, der Auskunft gab, wie der Kranke Lie pman n s ${ }^{84}$ ), hörte alle Worte wie "poht“, „pololo" usw. Leider finden sich exakte Angaben darüber nur in verhältnismässig wenigen Fällen. Es ist aber klar, dass in solchen Fällen alle direkt von der Wortperzeption abhängigen Funktionen, wie Nachsprechen und Diktatschreiben, ausfallen müssen.

Es gibt weiter eine Reihe von Fällen, ihre Zahl ist nicht sehr gross, wo die Kranken die Worte als solche richtig auffassten, denn sie konnten sie nachsprechen; den Sinn derselben vermochten sie dagegen nicht zu verstehen. Es bestand also partielle Worttaubheit mit kompletem Verlust des Wortsinnverständnisses.

In der Mehrzahl aller Beobachtungen aber liegen die Verhältnisse anders. Die Kranken sind in der Regel mindestens des Wortlaut-, meist auch des Wortsinnverständnisses nicht völlig verlustig gegangen. 
Sie reagieren noch auf ihren Namen, auf einzelne Worte, bekannte, erwartete und leicht fassliche Aufforderungen, auch dann aber reagieren sie nicht stets auf die gleichen Worte, der Umfang der Störung wechselt. In den leichtesten Fällen findet sich nur eine Unfähigkeit, den Sinn zusammenhängender Sätze oder gar längerer Wortfolgen, Reden usw. zu verstehen.

Ebenso ist in der Regel das Nachsprechen nicht aufgehoben. Es erhebt sich nur selten zu einer solchen Höbe, dass die Kranken ganze Sätze oder lange Worte fehlerfrei zu wiederholen vermögen, meist handelt es sich um die Repetition kurzer Phrasen und Worte, wobei oft genug noch Entstellungen, falsche und verstümmelte Worte produziert werden.

Nachsprechen und Wortsinnverständnis sind nun offenbar als die primitivsten die beiden Grundfunktionen, von denen man ausgehen muss, wenn man versucht, die gesetzmässige Abhängigkeit der Worttaubheit von lokalen Zerstörungen der Gehirnsubstanz festzustellen. Es ist ja sicher, dass für das wechselnde Verhalten der einzelnen Krankheitsfälle eine Reihe von Ursachen, insbesondere auch funktionelle Momente in Betracht kommen. Sieht man aber ab von Krankheitsprozessen, bei denen eine diffuse Schädigung mehr oder weniger ausgedehnter Hirnpartien, wie bei der senilen Atrophie, Tumoren und Abszessen oder infolge der Wirkung eines frischen, kaum iberwundenen Insultes mit Notwendigkeit vorauszusetzen ist, so ergibt die Berticksichtigung klinisch und anatomisch hinreichend genau beschriebener Fälle eine grosse Gesetzmässigkeit. Diese ist wohl imstande, uns lokaldiagnostisch wie als Korrektiv für die Ausgestaltung unserer theoretischen Anschauungen die wertvollsten Dienste zu leisten.

Nun bestätigt im allgemeinen meine Übersicht durchaus die alte Lehre (Wernicke, Bastian, Charcot, Naunyn u. a.), wonach etwa die hintere Hälfte der ersten Schläfenwindung, links bei Rechtshändern und umgekehrt (6 Fälle von rechtsseitigen Herden bei Linkshändern, v.Kussmaul ${ }^{76}$ ), Hecht 56 ), Touche $\left.{ }^{149}\right)\left[(I I, 2]\right.$, Nonne $\left.{ }^{104}\right)$, H. Köster ${ }^{74}$ ) und $\left.\mathrm{Banti}{ }^{9}\right)$ ), diejenige Stelle ist, deren Zerstörung Erscheinungen der Worttaubheit regelmässig nach sich zieht. Diese Regel hat aber eine ganze Reihe von Ausnahmen, die erst durch eingehende Berücksichtigung aller mitwirkenden Momente, zumeist wenigstens, verständlich werden.

Wir kennen klinisch negative Fälle mit dem hier als für Worttaubheit charakteristisch bezeichneten anatomischen Befund. In einer ganzen Anzahl derselben, auf die ich noch bei anderer Gelegenheit unten zurückkommen werde, ist der Frage der Rückbildung nicht genügend Rechnung getragen. Eine weitere Erklärungsmöglichkeit wird nahegelegt dadurch, dass man in einigen wenigen, aber gut beobachteten Fällen (Joffro ${ }^{65}$ ), Senat or ${ }^{14}{ }^{1}$ ), Molts chan off ${ }^{96}$ ) bei Rechtshändern 
als Grundlage der Worttaubheit eine Zerstörung der rechten ersten Schläfenwindung angetroffen hat. Die allgemeine Deutung nimmt bisher an, dass in diesen Fällen eine latente, nur durch die Erziehung verdeckte Linkshändigkeit vorgelegen habe, und es erscheint danach nicht ausgeschlossen, dass in manchen Fällen eben wegen vorwiegender Ausbildung der rechten Hemisphäre ein linksseitiger Herd die Erscheinung der Worttaubheit nicht hervorzurufen braucht. Immerhin bleiben in der Literatur noch einige Fülle bestehen (je ein solcher von Touche ${ }^{150}$ ) [F. 9], Lannois ${ }^{78}$ ), H. Köster ${ }^{75}$ ) und Spiller $\left.{ }^{96}\right)$ ), welche in dem oben bezeichneten Sinne klinisch als negativ anzusehen sind, also trotz der autoptisch festgestellten Zerstörung der ersten Schläfenwindung zu keiner bestimmten Erklärung Anhaltspunkte bieten. Dagegen kann man in zwei solchen v. Monakows, die Imbezille, beziehungsweise Idioten ${ }^{98}$ ) mit linksseitiger Porencephalie obne Sprachstörung betrafen, wohl ohne weiteres eine vikariierende Ausbildung der anderen Hemisphäre für die Funktionen der linken voraussetzen. Endlich waren in 3 von Touch $\left.{ }^{150}\right)[F .1]^{149}$ [II] und von Dana u. FränkeI ${ }^{10}$ ) beschriebenen Fällen noch erhebliche Teile der in Betracht kommenden Windungsgebiete erhalten, welche das Fehlen einer ausgesprochenen Worttaubheit auch ohne weitere Hilfsannahmen erklärlich erscheinen lassen.

Betrachten wir die Ausnahmen von unserer Regel nach der anderen Seite, so kennen wir eine Anzahl klinisch positiver Fälle, in welchen der Herd die erste Schäfenwindung verschont, aber andere Partien zerstört hatte. Da ich von allen diffus wirkenden Schädlichkeiten hier absehe - am schönsten illustriert dieselben ja der bekannte Fall Oppenheims, in dem ein Tumor im unteren Scheitelläppchen beim Aufrichten Worttaubheit machte, die im Liegen wieder verschwand -, muss ich zunächst die ausschliessen, bei welchen die Schilderung des Herdes alles zu wünschen übrig lässt, so die Fälle von M. Thoma's ${ }^{148}$ ), Hammond $I^{53}$ ), auch den von Bonhöffer ${ }^{19}$ ), dessen traumatischer Herd ja nur in vivo bekannt war. Vielfach handelt es sich weiter um Fälle, wo eine tiefe Läsion entweder das Mark, den Stabkranz der Schläfenwindung $\left(J_{0} l l y^{68}\right)$ u. a.) oder mit der Hörstrahlung den inneren Kniehöcker zerstört hatte (Tou che ${ }^{150}$ ) [F.14], Henschen ${ }^{61}$ ) [II] (vergl. Anhang 6), oder endlich zwar nicht die erste Schläfenwindung, wohl aber eine Windung, deren Bedeutung erst durch Flechsig erkannt ist, die temporale Querwindung. Der Schluss auf die Bedeutung der letzteren wird nahe gelegt zunächst durch theoretische Gründe. Wir wissen, dass die temporale Querwindung die eigentliche Endstätte der kaum darüber hinaus in der ersten Schläfenwindung sich ausbreitenden Hörstrahlung ist. Nun ist bekannt, dass durch Herde im Stabkranz zugleich mit Zerstörung des Balkens eine Worttaubheit hervorgerufen werden kann. Man hat diesen Sitz des Herdes als obligatorisch für die klinische 
Form der reinen Sprachtaubheit hingestellt, worüber später mehr. Allerdings besitzen wir nur den einzigen klinisch einwandfreien, anatomisch leider nicht ebenso reinen Fall Liepmanns als Beleg dafür, dass ein subcortikaler, im Mark des Schläfelappens Hörstrahlung und Balkenfasern mindestens der ersten Schläfenwindung zerstörender Herd eine solche herbeizuführen vermag. Weitere allgemein gültige Folgerungen wird man aus diesem so lange nicht ziehen können, bis die regelmässige $\mathrm{Ko}_{\mathrm{O}}$ incidenz des gleichen Herdes mit den gleichen klinischen Erscheinungen nachgewiesen ist.

Wohl aber lässt sich eine Einschränkung bezüglich der Bedeutung subcortikaler Läsionen der Hörstrahlung schon jetzt machen. Wir kennen nämlich Fälle, in denen bei genauer, auch mikroskopischer Untersuchung die Hörstrahlung bis auf geringe Reste sich unterbrochen zeigte (Quensel118), Fall D. u. E.; (Dejerine und A. Thomas ${ }^{39}$ ), partielle Zerstörung des ínneren Kniehöckers), in welchen gleichzeitig die Balkenfaserung des Schläfenlappens in hohem Grade oder völlig unterbrochen war, und in denen dennoch bei intakter Rinde der Querund ersten Schläfenwindung eine Worttaubheit weder bestand, noch je bestanden hatte. Es genügt danach ein Bruchteil der zentralen Hörleitung, um die Perzeption der Wortlaute in ausreichender Weise aufrecht zu erhalten. Eine funktionell qualitative $\nabla$ erschiedenheit ihrer Elemente, auch eine durch ihre Einschaltung bedingte, lässt sich danach wohl kaum annehmen, keinesfalls eine regelmässige Verteilung solcher in der Hörleitung.

Der Schluss liegt nahe, dass ausser Zerstörung der Hörleitung besonders eine solche der temporalen Querwindung geeignet sein müsse, eine totale Worttaubheit hervorzubringen, $d$. h. die totale Unterbrechung der zuleitenden Bahn in ihrer primären Rindenendstätte. Dem würden aus der bisherigen Literatur 3 Fälle entsprechen, nämlich ein Fall von Weiss $\left.{ }^{156}\right)$, vor allem aber ein solcher von Touche $\left.{ }^{150}\right)$ (F. 5), wo die Querwindung durch einen linksseitigen, nicht besonders grossen Herd vernichtet war, und ein schöner Fall von Henneberg-Jolly ${ }^{59-67}$ ) mit Zerstörung der Querwindung links samt der Hörstrahlung, allerdings neben einem rechts ebenfalls im Mark des Schläfenlappens liegenden Herde. In diesen Fällen war die Worttaubheit eine totale.

Eine exakte Grundlage zur Entscheidung der Frage lässt sich aus der Literatur wegen der meist nicht hinreichend genauen anatomischen Untersuchung und der Nichtbeachtung der Querwindung zur Zeit nicht gewinnen. Selbst da, wo sie sonst erwähnt ist, in 16 bezw. im ganzen 20 Fällen (vgl. Anh. 1), ist über den Umfang ihrer Beteiligung nicht stets etwas angegeben, in einigen Fällen war sie nur z. T. mit ergriffen. Das gilt noch mehr in Fällen, wo ihre Beteiligung durch den Herd 
nur aus den Angaben tuber eine Zerstörung des hinteren Teils der Insel oder der Fossa Sylvii erschlossen werden kann.

Auf der anderen Seite bestanden in 20 Fällen von sicher totaler Worttaubheit, die ich sonst aufinden konnte (Anhang 2), stets sehr grosse linksseitige Herde als Grundlage derselben, deren Beschreibung bisweilen, wenn auch selten angibt, fast stets aber erschliessen oder doch annehmen lässt, dass neben dem Gyrus temporalis I, meist auch neben dem Gyrus supramarginalis und angularis die temporale Querwindung mit im Herde aufgegangen war. Es ist bemerkenswert, dass es sich in 10 von diesen Fällen um doppelseitige Schläfenlappenherde handelte. Dass gelegentlich auch bei einseitiger Mitzerstörung der Querwindung Worttaubheit vermisst werden kann, werde ich noch unten bei der Frage der Rückbildungsfähigkeit zu erwäbnen haben.

Jedenfalls hat der Schluss eine grosse Wahrscheinlichkeit für sich, dass zur Erzeugung einer totalen Worttaubheit die völlige Unterbrechung der zuleitenden Bahn entweder im subcortikalen Verlauf oder in ihrer ersten Rindenendstätte, Flechsigs primärer Hörsphäre, erforderlich ist. Dass ausnahmsweise auch einmal sehr grosse Herde imstande sein könnten, die letztgenannte von jeder Verbindung mit der übrigen Hirnrinde abzuschneiden, ist eine Möglichkeit, die natürlich nicht ganz von der Hand zu weisen ist. Nur wird man Obigem einschränkend hinzusetzen müssen, dass die Gesetzmässigkeit des Zusammenhangs zwischen Zerstörung der Hörleitung und ihrer Endstätte einer-, der totalen Worttaubheit andererseits ganz erst bei doppelseitigen Herden zum Ausdruck kommt, vielleicht, weil bei einseitigen oft eine schon normalerweise vorhandene, individuell verschieden stark ausgebildete Einübung auch der rechten Hemisphäre die Folgeerscheinung ausgleichen oder verdecken kann.

Unser Schluss auf die Bedeutung der Querwindung speziell für die Worttaubheit wird unterstïtzt durch Berb̈cksichtigung solcher Fälle, in denen im Gegensatz zu den bisher betrachteten bei soust sehr ausgedehnten einseitigen Herden (Gyr. temporalis I u. II, supramarginalis, angularis) die Querwindung in mehr oder weniger weiter Ausdehnung erhalten blieb. Ich selbst habe einen solchen Fall früher beschrieben ${ }^{118}$ ) (Fall A.), sehr ähnliche sind von Henschen ${ }^{161}$ ) (Fall 41), Pick ${ }^{116}$ ) (Fall 10) und von Touch e ${ }^{150}$ ) (Fall 3 u. 4) veröffentlicht. Sie zeigen übereinstimmend, dass Wortlaut- und Wortsinnverständnis erheblich eingeschränkt, aber wenigstens für kurze, sehr geläufige Worte, Fragen und Aufforderungen durchaus nicht aufgehoben waren. Auch waren die Kranken imstande, ganz kurze, höchstens ein- bis zweisilbige Worte nachzusprechen.

Wir haben es hier also so zu sagen mit einer Eigenleistung der Quer- 
windung za tun. In welchem Sinne das zu verstehen ist, ergibt eine einfache Überlegung. Funktionieren eines rezeptorischen nervösen Apparates bei anderen ist für uns nur erkennbar, soweit es in einem motorischen Apparat für uns erkennbare Ausdruckszeichen auslöst. Das kann in mehr oder weniger direkt reflektorischer Weise erfolgen. Eine völlig isolierte Sinnessphäre wäre für uns funktionell nicht vorhanden. Eine Erörterung dartiber, ob man gerade diese für den Sitz oder das Substrat von Vorstellungen halten kann, erschiene direkt absurd, denn das Auftreten solcher im Bewusstsein setzt stets eine Verbindung mit anderen Vorstellungsgebilden voraus, einen komplikatorischen Vorgang, dem man auch ein aus noch mehreren Elementenkomplexen bestehendes Substrat zuerkennen muss.

Nun ist in den angeführten Fällen stets eine Verbindung zum motorischen Sprachzentrum in der 3. Stirnwindung vorhanden unter der Basis des Operkulums im unteren Teil des Fasciculus arcuatus, vielleicht auch indirekt über die Insel, über deren Verlauf ich an anderer Stelle ${ }^{118}$ ) berichtet habe. Diese Gebiete scheinen samt der Querwindungswurzel, wohl infolge ihrer Nähe zu den Zentralganglien, unter besonders günstigen zirkulatorischen Bedingungen zu stehen gegenüber Erkrankungen des Arteria fossae Sylvii, zumal in ihrem hinteren Stromgebiete. Das Nachsprechen dabei erklärt sich einfach, die Merkfähigkeit für Sprachlaute ist offenbar sehr begrenzt. Ob man in diesen $\mathrm{Fällen}$ die vorhandenen, bezw. sich bald restituierenden Reste des Sprachverständnisses durch die Verbindung mit Stirn- und Zentralhirn, also dem motorischen Sprachfelde erklären soll oder durch die im Gyrus supramarginalis erhaltenen Reste des hinteren Hemisphärenanteils, bleibe dahingestellt. Bisweilen bleibt auch, wie ich es (l. c. Fall A.) zeigen konnte, gerade ein Teil des zur anderen, rechtsseitigen Querwindung und zum rechten Schläfenlappen hinüber leitenden Balkens erhalten, so dass auch die Überleitung der eintreffenden Eindrücke auf die andere Hemispäre das erhaltene Sprachverständnis erklären könnte.

Jedenfalls lassen diese Beobachtungen den diagnostisch wichtigen Schluss zu, dass bei noch vorhandenen Resten von Sprachverständnis und Nachsprechen nicht mehr erwartet zu werden braucht, als die Intaktheit mindestens eines Teiles der Querwindung mit ibren Verbindungen zum motorischen Sprach- (resp. Aphasie-)felde, vielleicht auch mit einem Teile ihrer Balkenfasern.

Nun verhält sich klinisch weitaus die Mehrzahl der Fälle von Worttaubheit bezüglich Wortverständnis und Nachsprechen, wie ich schon sagte, prinzipiell gar nicht von den zuletzt angeführten abweichend. Von 88 Fällen mit ausreichender klinischer Beschreibung war das peutsche Zeitschr. f. Nervenheilkunde. 35. Bd. 
Nachsprechen 46 mal nur partiell erhalten mit meist paraphasischen Veränderungen, in der Regel konnten die auch nur partiell worttauben Kranken wenigstens 1- und 2 silbige Worte nachsprechen, bisweilen auch etwas mehr. In 27 Fällen fehlte das Nachsprechen vollkommen, in 17 Fällen neben einer totalen Worttaubheit $10 \mathrm{mal}$ ohne solche, oder doch, ohne dass dieselbe bestimmt angegeben wäre. Gut erhalten war es trotz fehlenden Wortsinnverständnisses angeblich in 15 Fällen.

Speziell für die Frage der Lokalisation sind nun 7 Fälle nicht verwertbar, weil sie nur klinisch beobachtet sind. Weitere 14 Fälle scheiden aus, weil es sich bei ihnen um diffuse Veränderungen im Gehirn handelte. Zur Prüfung der Frage, inwieweit sonst aus dem Stande des Nachsprechens sich besondere Schlüsse ableiten lassen, dürften nun nicht so die Fälle geeignet sein, deren partieller Worttaubheit Reste der Fähigkeit nachzusprechen korrespondierten, sondern vorzugsweise die einander entgegengesetzten Extreme.

Beobachtungen, in welchen das Nachsprechen absolut fehlte, verstehen sich von selbst bei totaler Worttaubheit, also in den oben genannten Fällen. Nicht stets finden sich indes ausdrückliche Angaben. Vorhanden waren solche in 15 Fällen (Anhang 3), bedingt stets durch grosse, in 7 Fällen davon sogar doppelseitige Herde. Obendrein fand sich 5 mal teils motorische Aphasie oder Beteiligung der Zentralwindungen. Dahin gehört ausserdem auch der Li ep mann sche ${ }^{84}$ ) Fall von sogen. subcortikaler sensorischer Aphasie. Ausser diesen kommen 5 Fälle in Betracht, wo bei nicht totaler Worttaubheit die Fähigkeit des Nachsprechens fehlte. In einem derselben (Bullen ${ }^{26}$ )) war die Worttaubheit, bedingt durch grossen doppelseitigen Schläfenlappenherd, sehr hochgradig; daneben bestand noch eine rechtsseitige Hemiplegie, der Herd reichte in die Zentralwindungen hinein. Auch die übrigen Fälle (von Bruns ${ }^{23}$ ), Collins ${ }^{33}$ ) u. a.) erklären sich durch Herde in den Zentralwindungen, der Brocaschen Region oder der Insel, soweit die Beschreibung eine ausreichende ist.

Den Gegensatz bilden Fälle ohne Wortverständnis, aber mit erhaltenem Nachsprechen, diejenigen, welche vornehmlich zur Trennung von Wortlaut- und Wortsinnverständnis den Anlass gegeben haben. Sobald man allerdings hier grössere Anforderungen stellt, schrumpft die Zahl der brauchbaren, mit Autopsie verbundenen Fälle auf sehr wenige zusammen. So dürften die Fälle von Claus ${ }^{32}$ ) (Fall 1), wohl auch von Leva ${ }^{80}$ ) (Fall 4) hier auszuscheiden sein, bei denen die Angaben sehr dürftige sind. Der Fall von Bonhö ffer ${ }^{19}$ ) muss zu den transitorischen, lokalisatorisch unklaren gerechnet und wohl z. T. durch Fernwirkung des traumatischen Herdes erklärt werden. Es bleiben alsdann eigentlich nur 4 stabilere, durch zirkumskripte Herderkrankungen bedingte 
übrig. Der eine derselben ist der bekannte Heubnersche ${ }^{63}$ ) Fall, bei dem durch einen Herd der hintere Teil der ersten Schläfenwindung in der Kollateralfurche und im Gyr. supramarginalis geradezu umschnitten war. Ganz analog verhält sich ein Fall von Touche ${ }^{150}$ ) (Fall 14), anatomisch ungemein ähnlich, klinisch worttaub bei intaktem Nachsprechen, aber mit einer Alexie, auf deren Erklärung ich erst später eingehen will. Man kann hierher eventuell rechnen einen weiteren Fall von Touche ${ }^{149}$ ) (II, 2) und den oben erwähnten von Leva, endlich vielleicht einen Fall von de Rod ${ }^{122}$ ). Soweit ich denselben kenne, waren hier vorderer Teil der ersten und zweiten Schläfenwindung durch einen Schusskanal verletzt, der sich dann subcortikal in das Mark des Schläfen- und Hinterhauptlappens fortsetzte. Das Nachsprechen war hier nicht völlig intakt, aber doch relativ gut, der hintere Teil der ersten Schläfenwindung war erhalten.

Jedenfalls legen diese Fälle die Folgerung nahe, dass zur Auffassung längerer Worte und von Sätzen und zu einer das Nachsprechen derselben ermöglichenden Retention, d. h. Merkfähigkeit für Wortklangbilder und Verknüpfung solcher ausser der Querwindung auch ein erheblicher Teil der ersten Schläfenwindung erforderlich ist, abgesehen natürlich von der assoziativen Verbindung mit dem motorischen Sprachfeld.

Man darf aber dabei nicht übersehen, dass gelegentlich die Leistungen dieses anatomischen Komplexes auch einmal geringer ausfallen können, so z. B. in einem Falle von Pick ${ }^{116}$ ) (Fall 9), der anatomisch dem vom Heubner beschriebenen sehr ähnelt und von Pick selbst als transcortikale Worttaubheit gedentet ist. Er versteht unter derselben allerdings auch nur eine "partielle Worttaubheit, bedingt durch partielle Läsion des Wortklangbildzentrums".

Man hat nun früher auf Grund theoretischer Überlegungen (ins* besondere Wernicke, Lichtheim, z. T. fräher auch Dejerine u. a.) eine erhebliche, ja unbedingte Abhängigkeit der Lesefähigkeit von der Intaktheit des Wortverständnisses, bezw. des Wortklangbildzentrums gefordert. Das Lesen von Worten, ja von Buchstaben führe erst zum Verständnis durch Anregung des Klangbildes im Klangbildzentrum. Dessen Zerstörung mache ein Lesen unmöglich, seine Abtrennung von der übrigen Rinde (die im Falle Heubners z. T. realisierte Form der transcortikalen sensorischen Aphasie) liesse die Fähigkeit, laut zu lesen, aber ohne Auffassung des Sinnes bestehen. Demgegenüber zeigt uns die klinische Erfahrung, dass die Kombinationen zwischen Störung des Wortverständnisses und Lesefähigkeit sehr viel mannigfaltiger sind.

Ich habe 98 Fälle mit anatomischem Befunde auffinden können, die hierüber Angaben enthielten. Von diesen worttauben Kranken 
war bei einer sehr grossen Zahl, nämlich $51 \mathrm{mal}$, die Lesefähigkeit allerdings total aufgehoben. Sie war gestört in 27 Fällen und zwar in einer unregelmässigen Weise. Die Kranken vermochten Buchstaben und auch Worte meist nicht oder auch nur in sehr entstellter Weise zu lesen, lasen aber andere wieder in wechselnd grosser Zahl richtig, nicht stets die gleichen bei jeder Prüfung. In 7 Fällen lasen die Kranken nach ausdrücklicher Angabe noch und zwar in erheblicher Weise richtig laut vor, verstanden auch den Sinn des Gelesenen, in weiteren 13 lasen sie richtig laut vor, verstanden aber den Sinn des Gelesenen nicht. Man könnte die Zahl der Fälle leicht noch um solche vermehren, die bei nur klinischer Beobachtung Störungen der einen oder anderen Art in klarer Form darboten. Es lag mir aber daran, zumal mit Rücksicht auf das doch garnicht seltene Vorkommen ganz der gleichen Formen von Alexie selbständig, auch ohne begleitende Worttaubheit, zu ermitteln, ob etwa die Alexie als gesetzmässige Folgeerscheinung des Ausfalls des sog. Wortklangbildzentrums betrachtet werden kann, ob sie gebunden ist an Zerstörung der oben als für Erzeugung der Worttaubheit wesentlich ermittelten Stellen, oder ob sie von der Zerstörung besonderer Hirnpartien abhängt.

Bei dieser Ermittelung müssen nun 12 Fälle ausscheiden, weil sie durch diffuse, bezw. durch diffus wirkende Krankheitsprozesse bedingt waren. Die Gruppierung der anderen Fälle drängt allerdings zu einer ganz bestimmten Entscheidung hin. Am eindeutigsten sind jedenfalls die Fälle mit totaler Alexie (vgl. Anhang 4). Hier beschränkte sich der Herd fast nie auf die Stelle der Worttaubheit. In 2 Fällen erklärte sich die Wortblindheit offenbar durch eine erhebliche Beteiligung des Hinterhauptlappens. In 39 Fällen reichte der Herd stets weit in das untere Scheitelläppchen, speziell auch in den Gyrus angularis hinein. Abweichend verhielten sich eine kleine Anzahl von Fällen. Von diesen sind 3 (je 1 Fall von Leva ${ }^{80}$ ) (I), Hammond ${ }^{55}$ ) (II) und M. Thomas ${ }^{148}$ ), wenigstens nach der anatomischen Seite hin, ganz unzureichend beschrieben. Über einen Fall von Hecht, der mir nur im Referat bekannt ist, muss ich mich des Urteils enthalten. In einem Fall von Touche ${ }^{150}$ ) (F. 5) war der Gyrus angularis selbst erhalten, aber durch einen Herd im Gyrus supramarginalis von seinen Verbindungen grossenteils abgeschnitten. Vielleicht sind in ähnlicher Weise ein weiterer Fall von Touche ${ }^{150}$ ) (F. 11) mit grossem Herd in Stirn-, Schläfenlappen und Gyrus supramarginalis zu erklären und ein Fall von Sano ${ }^{130}$.

Der Annahme, dass in diesen Fällen schon die Zerstörung des sog. Wortklangbildzentrums die Ursache der Wortblindheit sei, widersprechen diejenigen $\mathrm{F}$ älle, in welchen ausdrücklich angegeben ist, dass das Lesen 
nicht verloren gegangen, bezw. gestört gewesen sei. Dahin gehören in erster Linie die, welche erhaltenes Lautlesen bei Verlust des Verständnisses für den Sinn des Gelesenen zeigten. Es sind dies 8 Fälle, z. T. mit totaler Worttaubheit und Zerstörung der ersten Schläfenwindung. Es ist sehr wichtig, dass in 7 von denselben das untere Scheitelläppchen und speziell der Gyrus angularis nicht erweicht war. Nur ein Fall von Touch ${ }^{149}$ ) (II, F. 2) zeigte Zerstörung dieser Windung neben dem übrigen reehtsseitigen Herde rechts bei einem Linkshänder, der aber gewöhnt war, mit der rechten Hand zu schreiben.

In 7 Fällen ist weiterhin das Lesen angeblich unbeeinträchtigt gewesen, d. h. es bestand wenigstens die Fähigkeit laut zu lesen und das Gelesene zu verstehen bis zu einem nicht unerheblichen Grade fort. Diese Fälle sind um so wichtiger, als sie z. T. beweisen, dass, wie auch Monakow ${ }^{97}$ ) hervorgeboben hat, die schriftliche Verständigung selbst bei doppelseitigem Herde in der ersten Schläfenwindung nicht unmöglich zu sein braucht (Fälle von Mills ${ }^{92}$ ), Mott ${ }^{101}$ ), Pick ${ }^{113}$ ), Anton ${ }^{3}$ ) [F. 3]). Die Alexie ist also nicht notwendige Folge einer Zerstörung der Worttanbheitsregion, bezw. vor allem der ersten linken Schläfenwindung. Soweit die Lesefähigkeit wirklich intakt war, finden wir auch in diesen Fällen den Gyrus angularis nicht beteiligt, ausser angeblich wieder in einem Falle von Touche ${ }^{149}$ ) (I, F.2). Hier schob sich der Herd gegen den Gyrus angularis im unteren Teile vor. Es handelte sich um einen Kranken, dessen Sprachstörung schon 3 Jahre bestand und der inzwischen mit der linken Hand schreiben gelernt hatte. In einigen Fällen war das untere Scheitelläppchen teilweise lädiert, hier war aber doch die Lesefähigkeit auch nicht absolut intakt (z. B. Mott und Anton).

Insofern bilden dieselben den Übergang zu den Fällen partieller unregelmässiger Alexie, wie sie sich bei noch exakterer Untersuchung wahrscheinlich als das Häufigste ergeben würde. Auch hier unter 23 Fällen finden wir 18 mal eine Beteiligung des Gyr. angularis im Herde. Scheinbar abweichend sind ein Fall von Touche ${ }^{150}$ ) (F. 16), der nur den Gyr. supramarginalis ergriffen zeigte. In einem traumatischen Fall (Bonh ö ffer $\left.{ }^{19}\right)$ ) ist die Läsion nicht genau sichergestellt. In einem solchen von $\mathrm{Pick}{ }^{116}$ ) (F.4) bestand bei doppelseitigem Herde intra vitam rechtsseitige Hemiopsie und partielle Seelenblindheit, also jedenfalls eine links sebr tief nach innen und hinten greifende Läsion. Ein Fall von Ka uders ${ }^{72}$ ), mir nur im Referat zugänglich, war offenbar ebenfalls sehr kompliziert: motorische Aphasie, Hemiplegie, Hemianästhesie (Zerstörung von Insel, Claustrum, erster und zweiter Stirnwindung). Endlich bleibt ein Fall von Ballet 7 ), der sich zur Zeit allerdings überhaupt einer einfach lokali- 
satorischen Deutung entzieht (subcortikaler Herd im Mark der ersten Schläfen- und der Querwindung).

Nimmt man diese Tatsachen zusammen, so liegt allerdings der Schluss sehr nahe, dass für das Auftreten von Alexie neben einer Worttaubheit eine Beteiligung des unteren Scheitelläppchens, speziell des Gyr. angularis verantwortlich zu machen ist. Auf die Frage, wie man sich dessen Bedeutung für die Funktion des Lesens vorzustellen habe, will ich hier nicht näher eingehen. Sicher ist wohl, dass ein vollkommener Unterschied zwischen totaler und partieller unregelmässiger Alexie nicht besteht, Dinge, auf die ich an anderer Stelle zurückkommen will. Als feststehend kann angesehen werden, dass bei alleiniger Zerstörung der Worttaubheitsregion jede Lesestörung gröberer Art fehlen kann, und dass man höchstens berechtigt ist, eine Störung des Leseverständnisses zu erwarten, während das Lautlesen ungestört von statten geht. Diese Form der Störung beweist durchaus nicht, dass das sogen. Wortklangbildzentrum, dass die hintere Hälfte der ersten Schläfenwindung und Querwindung selbst erhalten sind, sondern findet sich auch bei eventuell sogar doppelseitiger Zerstörung dieser Stelle.

Wir haben es hiernach bei der Alexie mit einer relativ selbständigen Störung, beim Nachsprechen mit einer festen, an die Wortauffassung gebundenen primitiveren Funktion zu tun. Gleichwohl entscheidet diese Stellung zur Worttaubheit allein nicht äber die Intensität der beiden Störungen im Krankheitsbilde relativ zu einander. Beide Funktionen können bei einer sie gemeinsam beeinträchtigenden Herderkrankung in verschiedener und dabei wechselnder Weise neben Worttaubheit vorhanden sein. Ich verweise anf Fall 2 und 3 der vorliegenden Publikation als klinische Belege, dass jedenfalls nicht stets die ursprünglichere, festere Funktion, wie die funktionelle Betrachtungsweise dies generell nahelegen könnte, leichter und besser erhalten sein muss. Anch Lese-, also Schriftverständnis und Wortklangsinnverständnis sind, wie speziell Fall 3 beweist, nicht so gesetzmässig einander übergeordnet. Hier war die sekundäre Funktion weit besser erhalten. Ich führe diese Fälle nur als illustrative Beispiele an, doch lassen sich ähnliche Erfahrungen auch sonst, wie schon aus obigen Zahlen hervorgeht, in grösserer Menge anführen.

Die theoretisch angenommene gesetzmässige Abhängigkeit der Alexie von der Worttaubheit lässt sich also nicht aufrecht erhalten. Anders liegt das mit einer anderen Erscheinung, mit den Störungen der sog. inneren Sprache. Es kommt für die spontane Ausdrucksfähigkeit vorwiegend in Betracht die amnestische Störung, die Erschwerung der Wortfindung. Diese beherrscht bei der Worttaubheit vornehmlich die Ausdrucksfähigkeit und behindert die klare Satzbildung, während die einfache gram- 
matische Ordnung, die Verwendung der kleinen Satzteile, der Verben, die Stellung der Worte an sich nicht gestört zu sein pflegt oder doch braucht. Man pflegt dieselbe auf den Ausfall, die Störung in der Evokation des Wortklangbildes im Bewusstsein zu beziehen. Der amnestischen Störung meist parallel geht dem Grade nach auch die Störung: der Wortbildung, Paraphasie oder Jargonaphasie. Angaben über diese Erscheinungen haben sich in 180 Fällen erheben lassen. In der Mehrzahl, nämlich $91 \mathrm{mal}$, bestand eine ganz ausserordentliche, bisweilen totale Amnesia verbalis mit Jargonaphasie, selten eine völlige Wortstummheit. In 47 Fällen fand sich nur eine leichte Paraphasie oder fast ausschliesslich erschwerte Wortfindung. Nur in 2 Fällen von Adler ${ }^{1}$ ) u. Byron Bramw ell $\left.{ }^{29}\right)$ (F. 11) war die Störung der Spontansprache eine minimale. Als intakt zu bezeichnen war sie nur in 6 Fällen und auch hier (es sind die bekannten Fälle von Lich theim ${ }^{82}$ ), Liepmann ${ }^{84}$ ), Ziehl ${ }^{164}$ ) u. Henneb erg $\left.{ }^{58}\right)$ ) waren wenigstens vorübergehend leichte paraphasische Störungen einige Male vorhanden oder traten nach einiger Zeit zu der „reinen Worttaubheit" hinzu (Dejerine-Serieux ${ }^{38}$ ) und Gehuchten u. Goris $\left.{ }^{50}\right)$ ).

Diese abweichenden Fälle sind nun entweder nur klinisch beobachtet oder betreffen Kranke mit diffusen Veränderungen, wie die beiden zuletzt genannten. Nur der Fall Liepmanns zeigt einen subcortikalen Herd und macht die Annahme plausibel, dass die Erhaltung der Rinde der ersten Schläfen- und Querwindung für eine normale Erweckung des Wortklangbildes erhalten sein muss. Man kann bei der Regelmässigkeit der Störungen der Spontansprache sonst dagegen wohl umgekehrt mit Sicherheit schliessen, dass dieselbe eine notwendige Folge der Zerstörung der genannten Windungen ist. Aber auch bier ist zu bemerken, dass Art und Intensität der Sprachstörung nicht unbedingt von der Lokalisation des Herdes abhängig und dem Grade nach seiner Ausdehnung parallel seien. Wenigstens haben wir Fälle mit doppelseitiger Zerstörung der ersten Schläfenwindung, wie die von Pick ${ }^{113}$ ) (F. 3) und Anton ${ }^{3}$ ) (F. 3), in welchen die Wortfindung für konkrete Gegenstände, das empfindlichste Reagenz der Spontansprache, sich noch Ieidlich oder sogar gut erhalten zeigte. Andererseits bestand in einem Fall von Ballet ${ }^{7}$ ) mit wesentlich subcortikalem Herde von geringer Ausdehnung in der ersten Schläfenwindung eine erhebliche Paraphasie. Man kann also nur in allgemeinster Weise bei vorhandener Worttaubheit aus der Art der Störung der Spontansprache einen gewissen Schluss auf den Umfang des Herdes machen.

Nur kurz hingewiesen sei auf die besonders von Pick wiederbolt hervorgehobene Tatsache der Logorrhoe bei Worttauben und sensorisch Aphasischen überhaupt, die zwar keine absolut regelmässige, aber doch eine ungemein häufige Erscheinung darstellt. 
Über die Fähigkeit der Kranken, sich schriftlich zu äussern, geben die Krankengeschichten nur in meist sehr unvollkommener Weise oder gar keine Auskunft. Notizen habe ich $93 \mathrm{mal}$ gefunden. 45 Kranke vermochten überhaupt nicht zu schreiben, 34 mal fanden sich gewisse Reste spontaner schriftlicher Ausdrucksfähigkeit, in 14 Fällen, von denen allerdings 5 nur ganz unbestimmte Angaben liefern, soll dieselbe gut gewesen sein.

Nun basiert ja die Fähigkeit zu schreiben, soweit wenigstens die Spontanschrift in Frage kommt, auf der mündlichen, d. h. der Ausdrucksfähigkeit überhaupt auf der einen, der Schriftkenntnis auf der anderen Seite. Es lässt sich danach wohl erwarten, dass auch ihre Störungen von denen der beiden genannten Funktionen abhängig sein dürften. Tatsächlich lässt sich in der grossen Mehrzahl der Fälle die Agraphie der Worttauben von diesem Standpunkte aus ohne Schwierigkeit verstehen. Ich fand 41 mal auch autoptisch hinreichend genaue Angaben bei Fällen nicht diffuser Erkrankung, wo intra vitam komplete Unfähigkeit zu schreiben bestanden hatte. Von diesen Kranken waren $34 \mathrm{ab}-$ solut und 2 partiell alektisch. In 2 Fällen bestand die Agraphie neben motorischer Aphasie, die an sich schon geeignet war, die Schreibunfähigkeit zu erklären, in den übrigen rechtsseitige Hemiplegie, Seelenlähmung oder Ataxie.

Von 28 Fällen mit mehr oder weniger hochgradiger Paragraphie findet sich 14 mal zugleich partielle, 1 mal neben allerdings minimalen Resten von Schreibfähigkeit totale Alexie verzeichnet. In 2 Fällen fand sich bei gutem Lesevermögen eine motorische Aphasie als Ursache der Schreibstörung. In keinem der übrigen war die spontane Sprache iutakt, so dass kein Anlass, nach besonderen ursächlich oder lokalisatorisch wichtigen Momenten für die Schreibstörung zu suchen, vorliegt.

Damit soll über den diagnostischen Wert der Schreibstörungen an sich nicht abgeurteilt werden. Für die Auffassung der Worttaubheit und die Lokaldiagnose bei derselben haben sie aber wohl nur Wert, soweit ihr Fehlen gewisse Einschränkungen der voraussichtlich lädierten Partien gestattet, und auch das kaum über die Folgerungen hinaus, die sich aus dem Verhalten des Lesens und der spontanen Sprache zusammen ergeben.

Fälle, in denen die spontane Schreibfähigkeit der Kranken wirklich eine gute und als solche ausreichend dargetan war, sind ungemein selten. Nur in 2 Fällen, 1 von Liepmann ${ }^{84}$ ) und wohl auch einem solchen von $\mathrm{Pick}^{113}$ ), ist durch die Autopsie eine zirkumskripte Herderkrankung als Grundlage derselben sichergestellt.

Es ist von hohem Interesse, dass in diesen wie den übrigen Fällen von reiner Worttaubheit neben der gut erhaltenen Spontanschrift die 
Fähigkeit, auf Diktat zu schreiben, völlig fehlte. Dies'erklärt sich aus dem Vorhandensein totaler, auch das Wortlautverständnis aufhebender Worttaubheit, ist also an sich ohne besondere Beweiskraft. Im allgemeinen folgt die Fähigkeit, auf Diktat zu schreiben, sonst durchaus dem Stande der spontanen Schreibfähigkeit auf der einen, der Worttaubheit auf der anderen Seite.

Etwas anders steht es mit der Fähigkeit, zu kopieren, das, soweit die spärlichen Angaben hierüber Auskunft geben, in der äberwiegenden Zahl der Fälle erhalten war, auch da, wo spontan und auf Diktat nicht geschrieben werden konnte. Es handelt sich hier ja um eine relativ einfache assoziative Leistung, die ihre besonderen, unabhängigen und wohl auch recht ausgiebigen Bahnen abwandelt.

Auf der anderen Seite darf man sich nicht wundern, dass auch das Kopieren gelegentlich bei sonst totaler Agraphie oder hochgradiger Paragraphie gewisse Störungen aufweisen kann, ja dass es gelegentlich, aber stets nur bei sonst auch totaler Agraphie unmöglich ist. Gerade für diese Fälle kann uns die Berücksichtigung der neueren Erfabrungen über Apraxie, die Liepmann ${ }^{84 a}$ a. b) als ein so ungemein bäufiges Symptom von Erkrankungen, zumal der linken Hemisphäre nachgewiesen hat, von Wert sein.

Es ist hier nicht der Ort, die verschiedenen Arten, Entstehungsweisen und die lokalisatorische Bedeutung der vielgestaltigen Erscheinung Apraxie zu berücksichtigen. Ich möchte nur nach einer Richtung ihre diagnostische Bedeutung bei Fällen von Worttaubheit beranziehen. Ich habe nämlich selbst einige Male bei solcher deutlichere apraktische Erscheinungen dann gefunden, wenn der Herd die unteren vorderen Abschnitte des Gyrus supramarginalis mit in seinen Bereich gezogen hatte ${ }^{118}$ ) (Fall A., ein neuerer Fall N.). Man findet auch in der Literatur gelegentlich Andeutungen eines solchen Verhaltens (Amid on $\left.{ }^{2}\right)[\mathrm{I}]$, vielleicht auch $\mathrm{Heubne{ } ^ { 6 3 } )}$ u. a.), doch lässt sich zur Zeit über die Gesetzmässigkeit eines Zusummentreffens noch keine sichere Aussage machen. Es dürfte wohl lohnen, in künftigen Fällen dieser Frage mehr Aufmerksamkeit zu widmen, da möglicherweise aus dem Ausbleiben jeder apraktischen Beimischung sich eine gewisse Begreuztheit des Herdes ableiten lässt. Vorhanden ist solche jedenfalls öfters (vergl. Fall 3).

Theoretisch weitgehende Folgerungen aus den bisherigen Ergebnissen abzuleiten, enthalte ich mich hier, wohl aber gestatten dieselben eine Stellungnahme zu den auch bisher schon abgegrenzten, z. 'T. aus der Theorie abgeleiteten und mit ihr übereinstimmenden Formen.

So ist ohne weiteres anzuerkennen, dass es eine "reine Wort- oder Sprachtaubheit" gibt. Klinische Fälle von Lichtheim, Ziehl, Henneberg (l. c.) u. a. belegen ein Krankheitsbild, das sich beschränkt auf 
totale (absolute) Worttaubheit mit Verlust des Nachsprechens und Diktatschreibens, während spontane mündliche und schriftliche Ausdrucksfähigkeit, Lautlesen, Leseverständnis, also innere und Schriftsprache vollkommen intakt sind. Da wir bei Zerstörung der in erster Linie wichtigen Rindenfelder sehen, dass in der Regel die innere Sprache doch eine Störung erleidet (ganz abgesehen selbst von der Fähigkeit, Worte zu buchstabieren usw.) so liegt es nahe anzunehmen, dass dieser Symptomkomplex, wie das der. Fall Liepmanns belegt, bedingt sei durch einen subcortikalen Herd in der Hör- und Balkenstrahlung. So gross ihre Wahrscheinlichkeit ist, durchaus bewiesen ist diese Folgerung noch nicht; dazu gehört, wie gesagt, der Nachweis der Regelmässigkeit des anatomischen Befundes. Andererseits sind die Gegenbeweise, durch welche man dartun wollte, dass auch andere und besonders doppelseitige Herde den gleichen Komplex hervorbringen können, meiner Meinung nach nicht stichbaltig. Hier haben wir nur den einzigen, nicht hinreichend ausführlieh beschriebenen Fall Picks ${ }^{113}$ ). Ausserdem ist die reine Sprachtaubheit, wie man mit gewissen Einschränkungen zugeben kann, beobachtet als transitorisches Stadium bei gewissen diffusen, wenn auch auf bestimmte Gebiete beschränkten Gehirnerkrankungen (A s cher ${ }^{4}$ ), Dejerine Sérieux ${ }^{38}$ ), z. T. auch Hebold ${ }^{57}$ ), Gehuchten u. Goris ${ }^{50}$ ) u. a.). Für diese kommen aber doch ganz andere Gesichtspunkte in Betracht, auf die ich bei Würdigung der sogenannten transcorticalen sensorischen Aphasie eingehen will.

A uch diese theoretisch postulierte Form, charakterisiert durch mechanisches Nachsprechen, Lautlesen, Diktatschreiben, Kopieren, bei Fehlen des Sinnverständnisses für Gehörtes und Gelesenes, Störungen der Spontansprache und Fehlen der spontanen Schrift, kommt nun tatsächlich, wenn auch wohl kaum je in schematischer Reinheit vor.

Sie findet sich allerdings nicht als stabiler Folgezustand gröberer umschriebener Herderkrankungen. Wohl aber sehen wir, wie auch aus meinen Darlegungen hervorgeht, dass ihre Erscheinungen teilweise, in wechselnder Vollständigkeit und Kombination durch derartige Krankheitszustände hervorgebracht werden können. Wir haben es dann zu tun mit einer teilweisen oder vollständigen Zerstörung der ersten Schläfen- und der Querwindung, also derjenigen Stelle, die als Wortklangbildzentrum bei der sogenannten cortikalen oder zentralen Worttaubheit zerstört sein sollte. So kann im einzelnen, wie ausgefübrt, das Lesen auch bei totaler Zerstörung ungestört, oder doch als sinnloses Lautlesen erhalten sein. Das Kopieren ist meist intakt, das Nachsprechen immer partiell erhalten, soweit wir es nicht mit totaler (absoluter) Worttaubheit zu tun baben. Nur die Störung des Spontansprechens ist konstant, aber ihre Intensität wechselt. Das Verhalten der anderen Funktionen ist von untergeordneter, sekundärer Be- 
deutung, aber auch nicht gleichmässig. Kurz, es stellen sich uns die Erscheinungen der transcortikalen sensorischen Aphasie, wie das auch A. Pick ${ }^{116}$ ) schon längst betont hat, dar als die Symptome einer, anatomisch gesprochen, partiellen Zerstörung des sog. Wortklangbildzentrums. Die sogen. cortikale Worttaubheit bildet keine Einheit, sondern praktisch ein nach verschiedenen Richtungen hin wechselndes Krankheitsbild, für welches nur Störungen des Wortsinnverständnisses, des Nachsprechens und der Spontansprache von wesentlicher Bedeutung sind.'

Können wir uns nun schon jetzt eine Vorstellung von dem Bau und der Bedeutung der hier im einzelnen betroffenen Gebiete machen? Von der Bedeutung der Querwindung war bereits oben (S. 48) die Rede. Sie muss als der Ausgangspunkt der der Verbreitung und Verknüpfung akustischer, hier speziell der Sprachlaut-Empfindungen und Wahrnehmungen dienender Bahnen angesehen werden. Solche lassen sich, wie ich an anderer Stelle ${ }^{118}$ ) ausgeführt habe, auch in ausgedehntem Maße nachweisen. Und zwar ziehen aus der primären Hörsphäre Faserzüge 1. a) zur Insel und von da indirekt nach vorn zur dritten Stirnwindung. Ausgedehnter b) sind die Assoziationsbahnen zur Basis des Operculums, in demselben zum Gyrus supramarginalis und seinen einzelnen Abschnitten, weiter nach vorn (Fasc. arcuatus pars inferior) bis in die hintere Zentralwindung, vielleicht sogar bis in die vordere und den Fuss der dritten Stirnwindung. c) Es gelangen äusserst umfängliche Assoziationsfaserzüge zur ersten Schläfenwindung und von da zur Insel.

2. Die erste Schläfenwindung selbst besitzt starke Assoziationsfaserzüge zu den übrigen Schläfenwindungen, zum Gyrus supramarginalis, angularis, sowie zur konvexen Oberfläche des Hinterhauptlappens.

3. Wir finden reichliche Balkenfaserzüge fast aller dieser Gebiete, mit Ausnahme der spärlicher damit versehenen Insel, zu homologen, z. Teil wohl auch zu anderen Abschnitten der anderen Hemisphäre.

Nach den Hinweisen der Pathologie bin ich geneigt, die unter 1 aufgeführten Elemente als das Substrat anzusehen, dessen Erhaltung für das Nachsprechen unerlässlich ist. Dagegen dürften die unter 2 aufgeführten Elemente die gleiche Bedingung erfüllen für die psychologischen Funktionen des Sprachrerständnisses, der assoziativen Verbindungen der Klang- und Schriftbildvorstellungen und für die spontane Sprache. Endlich kommt für beide Funktionen, besonders für die letztgenannte, auch die Balkenfaserung mit in Betracht.

Natürlich muss man sich vor einem Schematismus hier allenthalben hüten. So haben z. B. erst letzthin wieder Lewandowsky ${ }^{51}$ ), früher Arnaud, Pick u. a. mit Recht darauf hingewiesen, dass es verschiedene Arten des Nachsprechens gibt. Unter Umständen stellt dasselbe eine durchaus spontane, willkürlich ablaufende Funktion dar, der man das 
rein mechanische Nachsprechen gegenüberzustellen hätte. Auch das letztere, oft sogenannte echolalische Nachsprechen braucht indes nicht rein mechanisch zu sein, ist es sogar zumeist nicht, sicherlich nicht in den 6 Fällen der Literatur, wo die fragende Form des Nachsprechens ein gewisses Verständnis und Äusserungsabsicht bekundete. Nicht selten sieht man allerdings, dass Aufmerksamkeit und Intention das Nachsprechen direkt verschlechtern. Im ganzen scheint mir, dass die verschiedene Vollkommenheit des Nachsprechens, wie ich sie oben herangezogen habe, am ersten eine diagnostische Bedeutung beanspruchen kann, und dass für alle Formen des. Nachsprechens die mindestens teilweise Intaktheit des oben genannten Substrates erforderlich ist.

Da dasselbe von dem insbesondere dem Lesen dienenden räumlich, obschon nicht scharf geschieden, doch im grossen und ganzen getrennt ist, so sieht man leicht ein, wie bei dem ausgedehnten für Worttaubheit in Frage kommenden Areal jede Funktion für sich oder in relativ wechselnder Intensität befallen sein kann. (Hierfür sprechen auch neue von Heilbronner60a) veröffentlichte Erfahrungen.)

Wie erklären sich nun die Fälle, in denen klinisch das Bild der transcortikalen sensorischen Aphasie in reiner Form vorliegt. Durch einen groben Herd wird dasselbe, wie wir sehen, faktisch kaum je hervorgebracht, und wir könnten uns trotz des scheinbar zutreffenden Heubnerschen Falles ein derartiges Vorkommnis gar nicht erklären. Wir sehen seine Erscheinung aber realisiert 1. bei gewissen diffusen Erkrankungen, seniler Atrophie (Bis ch off ${ }^{17}$ ), Pick ${ }^{117}$ ), Liepmann ${ }^{83}$ ), ein eigener Fall); vor allem aber auch 2. bei Tumoren oder nach Blutungen, als Durchgangszustand progressiv oder regressiv verlaufender Krankheitszustände (Giraudeau ${ }^{57}$ ), v. Monakow ${ }^{97}$ ), Frän$\mathrm{kel}^{46}$ ), Bonhöfer ${ }^{19}$ ), Lewandowskg $\left.{ }^{81}\right)$ ). Hier findet sich wenigstens zeitweise eine ziemlich dentliche Scheidung der mechanischen Sprachleistungen von dem Bedeutungsgehalt.

Nun handelt es sich in den erstgenannten Fällen um einen relativ systematischen, bestimmte Faserkategorien elektiv und in besonderer Reihenfolge befallenden Krankheitsprozess. Bei demselben werden gerade die hochwertigen, sich spät entwickelnden Assoziationsfaserzüge zuerst und vorwiegend betroffen. Es ist vorstellbar, wenn auch noch nicht voll verständlich, dass die senile Atrophie als ein somit tief in die Struktur der Windungen und der Rinde eingreifender Prozess psychologische Vorgänge, deren physiologische Parallelvorgänge eine besondere Dignität besitzen, relativ isoliert zum Ausfall bringen kann. Es liefert darin die senile Atrophie in gewissem Grade das dirkte Gegenstück mancher atypischer Paralysen. Jedenfalls ist es kein Zufall, dass wir in einer ganzen Reihe von Paralysefällen eine Form der 
Worttaubheit finden, welche wenigstens ihren Anfang als reine Worttaubheit nimmt, wohl infolge vorwiegender Erkrankung der Projektionsfaserung (vgl. oben Hebold, Ascher, Strohmayer ${ }^{146}$ ), Sérieux und Faranier $\left.{ }^{138}\right)$ ).

Bei den transitorischen Störungen der zweiten oben erwähnten Art wird man nicht umhin können, die Mitwirkung gewisser funktioneller Momente zur Erklärung heranzunehmen. Auch hier besteht in der Regel eine diffuse, allgemeine Schädigung einer grösseren Hirnpartie durch eine herdförmig begrenzte Erkrankung. Dabei zeigt sich in der Progression zeitweise wieder das Bild einer elektiven Schädigung gewisser Faserkategorien, das der sog. transkortikalen Worttaubheit, oder in der Regression ähnlich wie bei rein funktionellen Erkrankungen (Pick, Reevolution $\left.{ }^{14}\right)$ ). Man würde dabei durchaus auskommen mit der Vorstellung, dass eben die verschiedenen Fasersysteme und Zellkategorien auch gegen gewisse funktionelle Schädigungen eine verschiedene Resistenz besitzen. Ihre vorübergehende Lähmung erklärte, dass auch in entfernten Gebieten repräsentierte Vorstellungsremanenzen nicht erweekt werden können. Einen Prozess, wie er dem von v. Monakow ${ }^{93},{ }^{100}$ ) eingeführten Begriff der Diaschisis entspräche, brauchte man dazu nicht anzunehmen.

Dass durch eine umschriebene herdförmige Erkrankung des Gehirns eine derart elektive Zerstörung von Fasern nicht zustande kommen kann, wie sie für ein Bild wie die transcortikale sensorische Aphasie als stabile Ausfallserscheinung $\mathrm{zu}$ fordern wäre, lehrt die einfache anatomische Betrachtung. Wir sehen überall Balken-, Assoziationsund vielfach auch Projektionsfasern untrennbar mit einander vermischt. Tatsächlich ist dies Krankheitsbild keine einfache Herderscheinung. Wir können aber überhaupt psychologische Grössen und Funktionen uns nicht mit ihrem Substrat in einfach landkartenartig umschriebener Weise in der Hirnrinde lokalisiert und voneinander abtrennbar vorstellen. Wenn man von einem Wortklangbildzentrum sprechen will, so kann man dies in gewisser Weise mit Rücksicht auf die oben geschilderten Tatbestände bezgl. des Wortverständnisses und des Nachsprechens tun. Dagegen ist die.Zerstörung oder Erhaltung desselben in der ersten Schläfenwindung nicht entscheidend für alle fräher von ihm abgeleiteten Folgen auf dem Gebiet der Schriftsprache. Das sogen. Zentrum ist nur ein Durchgangspunkt für eine Reihe komplexerer, nach Umfang, Intensität und zeitlichen Verhältnissen verschiedener assoziativer Vorgänge, die je nach dem Umfange und der Lage des Herdes in wechselnder W.eise in Mitleidenschaft gezogen werden. Von lokaldiagnostischer Wichtigkeit unter diesen sind vor allem die Fähigkeit des Nachsprechens und des Lesens, erst in zweiter Linie der Zustand der spontanen Aus- 
drucksfähigkeit und nur sekundär das Verhalten der Fähigkeit, zu schreiben.

Den tatsächlichen Verhältnissen entsprechend würde ich es für richtiger halten, wenn man speziell für die Herderkrankungen die alten und mit unseren anatomischen Vorstellungen überhaupt schwer vereinbaren Bezeichnungen der subcortikalen, cortikalen und transcortikalen Worttaubheit bezw. sensorischen Aphasie ganz fallen liesse. Klinischen und anatomischen Befunden würde es besser entsprechen, zu scheiden zwischen einer perzeptiven und einer assoziativen Form der Worttaubheit, die aber beide auch mit einander gemischt auftreten können. Es ist wahrscheinlich, dass die reine perzeptive am ersten durch einen subcortikalen Herd im Sinne Liepmanns zustande kommt. Charakteristisch wäre, dass dieselbe total bezw. absolut und dass sie unkompliziert ist; die Erfahrung lehrt, dass sie auch stabil zu sein pflegt, ein Umstand, der sich zur Zeit nicht ganz einwandfrei erklären lässt.

Die rein assoziative Form ist stets partiell und zugleich kompliziert, sie nähert sich nicht selten dem Bilde der We rnickeschen sogen. transcortikalen sensorischen Aphasie. Wahrscheinlich ist sie stets in mehr oder weniger hohem Grade rückbildungsfähig. Durch den Herd ist fast immer sowohl Rinde wie Mark in mehr weniger grossem Umfange zerstört.

Da die Querwindung sowohl die Projektionsfasern aufnimmt, als auch Assoziationsbahnen entspringen lässt, wird eine erheblichere Beteiligung derselben eine mehr oder weniger hochgradige Beimischung perzeptiver zur assoziativen Worttaubheit bedingen. Bei völliger Zerstörung derselben wird die Worttaubheit ebenfalls absolut sein, sie ist aber zugleich auch jmmer kompliziert. Über die Rückbildungsfähigkeit lässt sich zur 'Zeit etwas ganz Sicheres nicht aussagen.

Es erübrigt sich, noch kurz dem angeregten, diagnostisch, prognostisch und auch theoretisch wichtigen Punkte näher zu treten, der Frage nach der Rïckbildungsfähigkeit der Worttaubheit.

Tatsächlich ist diese durchaus nicht so allgemein und so hochgradig, als das heute gewöhnlich angenommen wird (anders Len nmalm ${ }^{79}$ a), gerade wie umgekehrt die Bastiansche Lehre von der Stabilität der motorischen Aphasie sich als sehr anfechtbar erwiesen hat (vergl. v. Monakow, Liepmann, eigene Erfahrungen). - Bezüglich der Worttaubheit stütze ich mich auf 119 Fälle, über die hinreichend ausführliche Angaben vorliegen. Darunter blieben (nach Ausschluss diffuser Hirnerkrankungen und funktioneller Störungen) stabil oder so gut wie unverändert 58 , es erfuhren eine mehr oder weniger erhebliche Besserung $41 \mathrm{Fälle}$, es wurden geheilt 17, von denen allerdings 2 zu gewissen Bedenken Raum bieten. 
9 unter diesen Fällen sind nur klinisch beobachtet, oft aber gerade durch den Verlauf besonders interessant. Hier sei nur hervorgehoben, dass die 4 darunter stabil gebliebenen gerade die Fälle sog. subcortikaler sensorischer Worttaubheit, bezw. reiner Sprachtaubheit darstellen (Lichtheim ${ }^{82}$ ), Adler $\left.{ }^{1}\right), Z_{i e h l^{164}}$ ) und Henneberg $\left.{ }^{58}\right)$ ). Der Untersuchung, welche Ursachen im allgemeinen für die verschiedene Verlaufsweise verantwortlich gemacht werden können, lege ich nur die zur Autopsie gekommenen Fälle zugrunde. Nun lässt sich eine strenge Scheidung schon in klinischer Beziehung schwer durchführen. Die Differenz zwischen den ungeheilten, stabilen und den nur gebesserten Fällen ist ja nur eine graduelle. Auch bei letzteren bleibt eine Worttaubheit bestehen, die allerdings im Umfange wechselt, bei ungünstigen Fällen sich auch auf einzelne Worte erstreckt (die beiden oben beschriebenen, klinisch beobachteten Fälle weisen je eine solche partielle, beide Male verschieden hochgradige Rückbildung auf), in günstigen oft nur bei sehr sorgfältig darauf gerichteter Untersuchung zutage tritt. Diese letzteren nähern sich sehr den geheiten Fällen. Wenn hier Differenzen bestehen, so wird man am ersten erwarten dürfen, dass sie beim Vergleich der extremsten Gegensätze zutage treten. Ich stelle daher den ungeheilten, stabilen Fällen die ganz geheilten gegenüber.

Nun sind allerdings, um mit ersteren zu beginnen (vergl. Anhang 5) auch diese unter einander nicht gleichwertig, und zwar in doppelter Hinsicht. Die Zeit, innerhalb welcher die Rückbildung eintritt, ist im einzelnen wechselnd. Wenn aber auch manche Fälle noch nach Monaten und Jahren heilen, so pflegt doch eine erhebliche Besserung sich meist schon nach den ersten Wochen, oft bereits nach wenigen Tagen einzustellen. Von 53 Fällen, die ich als stabile ansehe, dauerten bis zur Autopsie 23 über ein Jahr, einzelne über 10 bis zu 18 Jahren, 8 Fälle dauerten über $1 / 4 \mathrm{Jahr}, 7$ noch mindestens 1 Monat, meist deren 2-3. In den anderen Fällen konnte ich die genaue Zeit nicht feststellen, doch handelte es sich hier stets um eine längere Zeit hindurch stabile Worttaubheit. - Weiter war in 12 von diesen Beobachtungen der Verlauf tatsächlich ein progressiver, meist infolge begleitender diffuser Veränderungen. Man darf wohl v. Monakow darin ohne weiteres Recht geben, dass die Ausgleichung einer durch lokalen Herd vernichteten Funktion ceteris paribus schwerer, ja eventuell aufgehoben sein wird bei einer zugleich vorhandenen allgemeinen Schädigung des Gehirns. Allein ist dieser Faktor aber nicht ausschlaggebend, denn wir finden erhebliche Arteriosklerosen auch verzeichnet bei Fällen, die eine z.T. sogar weitgehende Restitution erfahren haben. Ebenso bekannt ist, dass das Alter eine gewisse Rolle spielt, die Mehrzahl der geheilten Kranken stand im 3.-4. Jahrzehnt. Allein entscheidend ist aber auch 
das Alter nicht, denn wir finden geheilte Fälle im Alter von 49 und 66 Jahren, erheblich gebesserte noch im Greisenalter, während Rückbildung auch bei ganz jugendlichen Individuen ausbleiben kann. Hinweisen möchte ich endlich auf eine weitere für die Rückbildung mitbestimmende Bedingung, nämlich die Schnelligkeit des Eintritts der Worttaubheit. Je langsamer dieser erfolgt, um so eher wird sich die Störung ausgleichen, so dạss sie bei sehr langsam wachsenden Tumoren eventuell ganz unbemerkt bleiben kann. Ich möchte mich bei voller Rücksicht auf diese auxiliären Momente hier vor allem der Frage zuwenden, inwieweit Ausdehnung und Lokalisation des Herdes geeignet sind, die Variabilität des Verlaufes zu erklären.

Bemerkenswert erscheint dass nicht in allen stabilen Fällen die Worttaubheit eine totale war, nämlich nur $27 \mathrm{mal} ; 26 \mathrm{mal}$ bestanden noch Reste von Wortlaut- oder Wortsinnverständnis. Wohl das wichtigste Ergebnis des Vergleiches ist, dass unter den ungeheilten Fällen sich nicht weniger als $21 \mathrm{mal}$ doppelseitige Herde im Bereich des Schläfenlappens fanden. Links war stets die für Worttaubheit bedeutsame Stelle zerstört, rechts meist ebenfalls, nur dreimal eine wenigstens naheliegende Partie (Gyr. supramarginalis, 2. und 3. Schläfenwindung, innerer Kniehöcker). 6 vou den Kranken waren gleichzeitig rindentaub. Man géht wohl nicht fehl, hierhin noch drei weitere Fälle von Rindentaubheit zu rechnen, über die mir nähere Notizen nicht zu Gebote stehen, so dass sich damit die Zahl der doppelseitigen Herde auf 24 unter 55 erhöhen würde.

Schliesse ich unter den übrigen Beobachtungen zuerst 5 aus, bei welchen neben dem Herde eine progressive Allgemeinerkrankung des Gehirns bestand, arteriosklerotische bezw. senile Atrophie mitProgredienz der klinischen Erscheinungen, erheblicher Demenz, so bleibt für 9 weitere ein sehr grosser linksseitiger Erweichungsherd zn verzeichnen, der erhebliche Teile des Schläfen-, Scheitel- und Hinterhautlappens, bisweilen auch Zentral- und Stirnwindungen in mehr oder weniger grosser Ausdehnung befallen hatte. In 7 Fällen war speziell die Beteiligung der Insel und der Querwindung hervorgehoben, 6 mal der Stabkranz von Schläfen- und Hinterhauptlappen in weitem Umfange lädiert.

Worin hier das für die Stabilität der Erscheinung entscheidende Moment liegt, ist schwer zu entscheiden. Es liegt aber, zumal nach den Erfahrungen bei Fällen relativ isolierter Frhaltung der Querwindung mit gewisser Rückbildung (vergl. oben) und in Anbetracht der zahlreichen Fälle nit doppelseitigen Herden nabe, der Erhaltung bezw. Zerstörung des Balkens ein besonderes Gewicht beizumessen.

Völlig widerspruchslos lassen sich aber die Erfahrungen nicht einheitlich ordnen, denn in einigen Fällen führten auch ziemlich begrenzte Herde 
eine monate- und jahrelang stabile, wenn auch nicht totale Worttaubheit herbei. Von diesen sind allerdings der eine (Nonne $\left.{ }^{104}\right)$ ) nur sehr kurz wiedergegeben, andere (Fraser ${ }^{47}$ ) und Pershing $\left.{ }^{110}\right)$ ) sind mir nur aus Referaten bekannt. Doch gibt es zweifellos Fälle (z. B. ein solcher von Dejerine und A. Thomas ${ }^{39}$ )), bei welchen die Entstehung und Persistenz einer totalen Worttaubheit sich aus dem Obduktionsbefund trotz genauer makro- und mikroskopischer Untersuchung nicht verstehen lässt. (Links bestand hier ein Herd in der 2. Schläfenwindung, Gyr. supramarginalis und angularis, nur wenig auf den hinteren Teil der 1. Schläfenwindung übergreifend.)

Auf der anderen Seite finden wir ähnliche Befunde auch bei Fällen, deren Worttaubheit später heilte. Ich habe wirkliche Heilung in Fällen mit späterer Autopsie aus der neueren Literatur eigentlich nur 6 einwandfreie sammeln können. In 2 Fällen von Touche ${ }^{150}$ ) (Fall 1 u. 16), 1 von Kahler ${ }^{70}$ ) bestand links eine recht ausgedehnte, zum Teil auf Stabkranz und Zentralganglien übergreifende Läsion. Wahrscheinlich gehören zu denselben auch eine Reihe von Beobachtungen, wo post mortem Zerstörung der Region der Worttaubheit sich fand, ohne dass eine solche intra vitam bemerkt worden wäre. Ältere Fälle dieser Art (von Perroud ${ }^{108}$ ), Trousseau 153), Broca ${ }^{25}$ ), Cotard ${ }^{34}$ ), Avonde, Charcot und Troisier ${ }^{132}$ )) hat

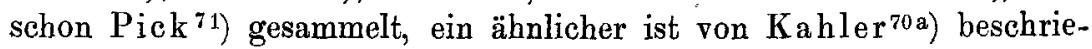
ben worden. In einigen anderen ist wenigstens eine schwere Aphasie ohne nähere Definition vorangegangen (Rosenthal ${ }^{124}$ ), Touche ${ }^{150}$ ) [Fall 16], Bastian 11)). Einzelne Fälle (Touche ${ }^{149}$ ) [II,2] und Brunet $\left.{ }^{22}\right)$ ) könnte man sogar der Beschreibung nach als residuäre Worttaubheit leichtesten Grades auffassen.

Wichtiger und interessanter aber sind die 3 noch restierenden, z. T. genauer beschriebenen Fälle der neueren Literatur und zwar, weil es sich in diesen sogar um doppelseitige Schläfenlappenerkrankungen handelte. Wenig präzis lautet die Angabe in dem Falle von Jolly ${ }^{68}$ ) (F. 1: symmetrische Herde im hinteren Drittel beider Schläfenlappen), dagegen fand Edgren ${ }^{41}$ ) in seinem Falle, trotz Affektion der 1. Schläfenwindung beiderseits, gerade links das hintere Drittel dieser Windung frei. Sérieux ${ }^{13}$ ) beschreibt Heilung der Worttaubheit bei doppelseitigen Herden im unteren Scheitelläppchen. Hier griff derselbe links auf die erste Schläfenwindung und Regio retroinsularis über. Die Worttaubheit heilte erst nach 2-5 Monaten bei den letztgenannten Kranken, bei Jollys Patient. erst nach 1 Jahr. Eine gewisse Verwandtschaft zu diesen Beobachtungen weist auch der bekannte, auf Kussinauls Anregung publizierte Fall von Körner ${ }^{73}$ ) auf, der beider- 
seits die erste Schläfenwindung erweicht zeigte, aber nur in ibrer vorderen Hälfte. Worttaubheit hatte nie bestanden.

Wie man sieht, ist es schwer, hiernach zur Zeit exakt zu formulieren, welche gemeinsamen Momente anatomisch die total rückgebildeten Fälle von Worttaubheit von den ganz stabilen unterscheiden. Wahrscheinlich spielt hierbei auch die vor der Erkrankung etwa vorhandene Mitwirkung der anderen (d. h. meist der rechten) Hemisphäre eine erheblicher Rolle. Jedenfalls ist bei den heilbaren Formen die Querwindung nicht selten verschont. Vor allem aber finden wir niemals doppelseitige Herde in der schon charakterisierten Partie (erste Schläfenund Querwindung), ja wir finden keinen Fall, in dem dieselbe links total oder erheblich zerstört wäre, während gleichzeitig rechts ein umfänglicher Herd in nächster Nähe dieser Region bestanden hätte.

Die Resultate meiner Zusammenstellung lassen sich kurz so formulieren:

1. Diejenige Stelle, durch deren Zerstörung Worttaubheit so gut wie stets hervorgerufen wird, umfasst etwa die hintere Hälfte der ersten Schläfenwindung einschliesslich der temporalen Querwindung, links bei Rechtshändern und umgekehrt, nur ausnahmsweise anders. Nur bei völliger Zerstörung auch der Querwindung kann man Worttaubheit sicher erwarten. Scheinbar abweichende Fälle erklären sich entweder durch Übersehen einer zurückgebildeten Worttaubheit oder durch tiefen Sitz des Herdes mit Unterbrechung des Stabkranzes.

2. Totale (absolute) Worttaubheit kann vorkommen:

a) bei subcortikalem Herd mit völliger Unterbrechung der Hörstrahlung und des Balkens der Worttaubheitsregion. Partielle Unterbrechung der Hörstrahlung (auch im inneren Kniehöcker) bei totaler Balkenunterbrechung, aber intakter Rinde der Quer- und ersten Schläfenwindung lässt Wortlaut- und Wortsinnverständnis intakt.

b) Totale (absolute) Worttaubheit bei ganz oder teilweise cortikalem Herd kommt vor, wenn links die Querwindung isoliert oder durch einen grossen Herd mit unterbrochen ist. Absolut gesetzmässig wird diese Folge erst bei gleichzeitiger Herderkrankung auch im rechten Schläfenlappen, auch wenn dadurch das Hörvermögen nicht völlig aufgehoben ist.

3. Fälle, in welchen bei grossem Herd links nur die Querwindung ganz oder partiell erhalten ist, zeigen regelmässig eine partielle, mehr oder weniger hochgradige Worttaubheit mit erhaltener Fähigkeit, einbis zweisilbige Worte korrekt, andere nur ganz paraphasisch nachzusprechen. Hier sind stets gewisse Verbindungen zum Felde der motorischen Aphasie, meist auch gewisse Balkenfaserverbindungen der Querwindung erhalten.

4. Das Nachsprechen fehlte bei nur partieller Worttaubheit stets 
nur, wenn zugleich Herde in der Brocaschen oder der motorischen Region bestanden.

5. Intaktes umfängliches Nachsprechen bei Worttaubheit setzt voraus, dass ausser Teilen der Querwindung auch noch erbeblichere Teile der ersten Schläfenwindung erhalten geblieben sind (Grundlage der Merkfühigkeit für und der inneren assoziativen Verknüpfung der Wortklangbilder). Doch brauchen nicht umgekehrt diese Funktionen bei Verschonung des genannten Gebietes vollkommen erhalten zu sein.

6. Störungen des Lesens sind mit Destruktion der oben umschriebenen Region der Worttaubheit nicht notwendig verknüpft, höchstens kann ein Verlust des Verständnisses des Gelesenen bei erhaltenem Lautlesen erwartet werden.

7. Vollkommene oder partielle Alexie (mit Ausnahme der unter 6 genannten Form) ist fast ausnahmslos beobachtet nur in Fällen, in welchen das untere Scheitelläppchen, speziell der Gyrus angularis, mindestens partiell mit zerstört war.

8. Die Störungen im Nachsprechen und Lesen stehen ihrer Intensität nach bei der Worttaubheit in keinem reg elmässigen Verhältnis zu einander.

9. Amnestische und paraphasische Störungen der Spontansprache fehlen bei der Worttaubheit nur ganz ausnahmsweise, niemals ganz bei Beteiligung der Rinde in der Worttaubheitsregion, ihre Intensität ist aber eine sehr wechselnde.

10. Die spontane schriftliche Ausdrucksfähigkeit bei der Worttaubheit zeigt sich durchaus abhängig a) von den Störungen der Spontansprache und b) von den Lesestörungen.

Die Störung der Diktatschrift hängt ab a) von dem Stande der Spontanschrift und b) von dem der Worttaubheit.

11. Wo auch die Fähigkeit, zu kopieren, bei Worttaubheit gestört oder ganz aufgehoben ist, entspricht dies entweder einer totalen Alexie oder aber, oft auch gleichzeitig, einer motorischen Störung, motorischen Aphasie oder Apraxie.

12. Beim Auftreten ausgesprochener apraktischer Erscheinungen in Fällen von Worttaubheit fand sich wiederholt, dass der vordere Teil des Gyrus supramarginalis vom Herde mit angegriffen war.

13. Für die theoretisch abgegrenzten Formen der Worttaubheit gilt Folgendes:

A) Anzuerkennen sind a) die reine Sprachtaubheit als klinisches Bild. Für ihre Entstehung durch subcortikalen Herd spricht bisher nur ein Fall. Anatomische Befunde liegen sonst nur vor bei transitorischem Vorkommen durch diffuse Krankheitsprozesse.

b) die sogenannte transcortikale sensorische Aphasie Wernickes, als klinisches Bild beobachtet und zwar meist nur transitorisch bei 
diffus wirkenden Krankheitsprozessen. Als direktes stabiles Herdsymptom ist sie in reiner Form nicht bekannt.

B) Dagegen ist c) die sogen. cortikale sensorische Aphasie eine dem klinischen Bilde nach sehr wechselnde Krankheitsform, deren Erscheinungen und Symptomgruppierung uns aber durch den Wechsel in Sitz und Umfang des Herdes unter Berücksichtigung der anatomischen Verhältnisse verständlich werden.

14. Bei der Einteilung der durch zirkumskripte Herderkrankung bedingten Formen von Worttaubheit vom klinisch anatomischen Standpunkte geht man am besten aus davon: Wir haben es im Gehirn zu tun mit einem relativ ausgedehnten, den vorwiegend akustisch bestimmten Sprachfunktionen dienenden Assoziationsareal, in welches an einer Stelle die akustische Projektionsfaserung eintritt. Diese Stelle, die temporale Querwindung, bildet eine Grenz- und Übergangsstation.

Alle durch einen tiefer peripher gelegenen Herd bedingte Worttaubheit könnte man als rein perzeptive bezeichnen, diese ist stets absolut, sie ist rein und nach der Erfahrung meist zugleich stabil.

Umgekehrt ist jede durch einen zentraleren Herd hervorgerufene Worttaubheit notwendig partiell, kompliziert und meist auch rückbildungsfähig. Rein assoziative Form.

Die mehr oder weniger erhebliche Beteiligung der Querwindung endlich schafft Mischformen perzeptiv-assoziativer Worttaubheit. Diese können partiell oder total sein; der rein perzeptiven Form gegenüber sind sie stets kompliziert, mindestens mit Störungen der Spontansprache, von den rein assoziativen trennt sie, auch wo sie nicht total sind, die Beschränkung in der Fähigkeit, nachzusprechen. Diese Fälle sind bald stabil, bald rückbildungsfähig.

15. Die Bedingungen, unter welchen eine Worttaubheit als direkte Herderscheinung sich zuräckbilden, selten ganz heilen kann, lassen sich noch nicht mit aller Sicherheit formulieren. In den stabilen Fällen handelte es sich oft um doppelseitige Zerstörung der Worttaubheitsregion, ebenfalls oft um einseitige Zerstörung auch der Querwindung im Bereich eines meist recht ausgedehnten Herdes. Wahrscheinlich spielt die Beteiligung des Balkens eine grosse Rolle. Nicht alle Fälle sind in dieser Hinsicht zur Zeit anatomisch-physiologisch zu erklären, auch Alter der Kranken, Allgemeinzustand des Gehirns und Dauer der Krankheitsentwicklung kommen in Betracht, möglicherweise endlich gewisse Dispositionen in der Aktion beider Hemisphären.

In den geheilten Fällen war nie die Region der Worttaubheit beiderseits total zerstört, oder auch nur links zerstört bei einem rechts in der Nähe gelegenen Herde. Heilung ist sonst auch bei grossem Herde und einseitig totaler Zerstörung der gedachten Gegend beobachtet. 
Nach Darlegung meiner allgemeinen Ergebnisse möchte ich nur noch wenige Worte zur Erläuterung der von mir selbst hier veröffent-. lichten Beobachtungen anfügen.

Fall 2 beginnt mit totaler Worttaubheit, Alexie, schwerer amnestisch-paraphasischer Störung der Spontansprache und Agraphie. Aber schon nach wenigen Tagen tritt Besserung anf und zwar zuerst im Lesen und Kopieren, dann erst im akustischen Wortverständnis und Nachsprechen. Zeitweise zeigt er die Erscheinung des fragenden Nachsprechens. Nach 3 Wochen macht sich die Worttaubheit nur noch komplizierteren Sätzen gegenüber bemerkbar, auch Nachsprechen und Diktatschreiben verhalten sich so, das Verständnis gelesener Sätze im Zusammenhang. ist noch mangelhaft, am ausgesprochensten sind die Erscheinungen von seiten der Spontansprache und Scbrift. Weiterhin erfolgt der Fortschritt so langsam, dass noch nach 2 Monaten deutliche Störungen in allen genannten Funktionen erkennbar sind. Es handelt sich also zweifellos um eine assoziative Form mit einer mässig ausgedehnten Zerstörung der Region der Worttaubheit. Wahrscheinlich reicht der Herd nach der Gruppierung der Erscheinungen mehr nach vorn.

Fall 3 zeigt allmählich nach Art einer Thrombose sich einstellende Erscheinungen aphasischer Art neben einer auch später sehr deutlichen rechtsseitigen Hemiparese. Es bestand eine von vornherein sehr partielle Worttaubheit, bei der Pat. nachzusprechen vermochte. Durch Nachsprechen erfolgte bisweilen noch nachträgliches Sinnverständnis, oftmals aber auch nicht. Stets war die schriftliche Verständigung mit ihr besser möglich als die mündliche. Gleichwohl bestanden auch alektische Störungen, vor allem partielles Feblen des Sinnverständnisses. Die Spontansprache war stark amnestisch-paraphasisch, die Schrift auch beim Kopieren ausser paragraphischen Störungen zittrig und ataktisch. Es bestand eine klar ausgesprochene Apraxie.

Auch hier trat eine, wenn auch nicht so wesentliche Besserung auf vornehmlich wieder im Lesen, das Nachsprechen ging schneller vorwärts als das Sprachverständnis, am deutlichsten blieben die Störungen der Spontansprache und Spontanschrift. Trotz der Fortschritte bestanden auch nach 4 Monaten noch deutliche Erscheinungen auf allen Gebieten.

Es handelt sich also auch hier um eine wesentlich assoziative Form der Worttaubheit ohne totale Zerstörung der fraglichen Region, aber mit Beteiligung auch des Gyr. supramarginalis im unteren Scheitelläppchen.

In dem besonders interessanten Fall 1, dessen Erscheinungen ich schon oben kurz zusammengefasst habe, hat inzwischen die Autopsie gezeigt, dass die schon intra vitam gestellte Diagnose im wesentlichen richtig war. Einige Besonderheiten scheinen aber doch noch der Beachtung wert. 
Zunächst haben wir es zu tun mit einer, wenigstens für den Wortsinn, nahezu vollständigen Worttaubheit, bei der aber das Wortlautverständnis nicht fehlte, da ein- bis zweisilbige Worte nachgesprochen wurden. Danach war, wie die Autopsie bestätigte, zu erwarten, dass ein Herd in der Worttaubheitsregion bestand, aber mindestens die Querwindung zum Teil verschonte. Die Lesefähigkeit war nicht aufgehoben, aber Pat. las ohne jedes Verständnis laut vor. Auch bestand keine Apraxie. Aus diesem Verhalten folgte, dass das untere Scheitelläppchen intakt sein würde.

Nun trifft diese Voraussagung allerdings nicht in vollem Maße zu. Der Herd lässt zwar das untere Scheitelläppchen selbst frei, reicht aber doch wenigstens in den Übergang zwischen zweiter Sehläfen- und Angularwindung hinein. Das Lautlesen war ja auch nicht in vollem Umfange, wennschon recht erheblich erhalten, NB. sogar bei einem doppelseitigen Herde. Ebenso hat sich ein besonderer Herd im hinteren oberen Teil des Gyrus supramarginalis ergeben. Dieser ist aber sehr oberflächlich und verschont ganz die vorderen unteren Partien der Windung.

Dass der Herd in der dritten Stirnwindung gerade die Brocasche Stelle freilässt und dass er für die fräher vorhandene transitorische Aphasie verantwortlich zu machen ist, habe ich schon oben ausgeführt.

- Es bleibt nur noch kurz des rechtsseitigen Herdes zu gedenken. Ich habe schon gelegentlich der Vorstellung des Kranken hingewiesen auf die auffallende Stabilität des Krankheitszustandes. Diese hatte auch den Gedanken an einen doppelseitigen Herd nahe gelegt. Aber einmal handelt es sich doch nur um eine Beobachtungszeit von zweimonatlicher Dauer, so dass eine Rückbildung wohl noch später erfolgen konnte. Weiter hatte mich noch eine weitere Beobachtung von dieser Annahme fortgeleitet. Wir sahen nämlich, dass der Kranke imstande war, alle Objekte nicht nur nach sonstigen Qualitäten, sondern auch allein nach ihren akustischen Eigenschaften zu erkennen. Vielleicht ist auf die Unaufmerksamkeit bei dieser Prüfung zu viel und auf leichte Störungen der Funktion zu wenig Gewicht gelegt, erhalten war sie auf jeden Fall. Wenn nun auch theoretisch eine Störung derselben in Fällen von doppelseitiger Erkrankung der ersten Schläfenwindung im allgemeinen wahrsçheinlich ist, so wird es doch besonders nach dem autoptischen Befund verständlich, dass eine solche nicht notwendig aufzutreten braucht, wofern nur mindestens Teile einer Querwindung in Verbindung mit der Nachbarschaft erhalten bleiben. Ich glaube, dass man auch in der Literatur den Fall Pick ${ }^{119}$ ) als einen Beleg ansehen kann, dass doppelseitige Herde der gedachten Art das akustische Objekterkennen nicht not- 
wendig aufzuheben brauchen. Oft sind derartige Kranken total taub, Angaben finden sich über den fraglichen Punkt nicht regelmässig. Man wird jedenfalls unsere Beobachtung künftig als einen Beweis für dieses Verhalten ansehen dürfen.

Über die musikalischen Fähigkeiten unseres Kranken haben wir leider genaueren Aufschluss trotz wiederholter Untersuchung nicht erhalten können. Dem Anschein nach war er, wenn auch vielleicht nicht absolut, musiktaub.

Wie ich glaube, illustriert der Fall sehr gut den Begriff der assoziativen Worttaubheit in einer Form, die sich der sogenannten transcortikalen in hohem Grade nähert.

Herrn Geheimrat Flechsig bin ich für die Überlassung der Krankengeschichten sehr zu Dank verpflichtet.

\section{Literatur.}

Der Raumersparnis wegen zitiere ich die Fälle mit den Nummern des ausführlichen Literaturverzeichnisses von v. Monakow in Ergebnisse der Physiologie. 6. Jahrgang. 1 u. 2. S. 334.

1) Adler 1942. 2) Amidon 1944. 3) Anton 1948. 4) Ascher, Ztschr. f. Psychiatrie. 5) Aronde zit. 1237. 6) Ball u. Séguin zit. 1944. 7) Ballet 2071. 8) Baltzer zit. 102 u. 79a. 8a) Banks, Dubl. Quarterl. Journ. of $\mathrm{m}$. sc. 1865. II. 9) Banti 1954. 10) Bastian 928. 11) Derselbe 1955. 12) Derselbe 929. 13) Bateman 931-933. 14) Berger zit. Wernicke 157. 15) Bernard 945. 16) Bernhardt 1959. 17) Bischoff 1962. 18) Bleuler 1677. 19) Bonhöffer 969. 20) Broadbent 962.'21) Bruce 1968. 22) Brunet 1001. 23) Bruns 1693 . 24) Derselbe 1970 . 25) Broca zit. 1237 u. 79 a. 26) Bullen 1007. 27) Bulteauzit. 1399. 28) Burckhardt 1970a. 29) Byron Bramwell 1966. 30) Charcot zit. 1237. 31) Chauffard zit. 1944. 31) Claus, Irrenfreund 1893. 33) Collins zit. Mendels Jahresbericht 1899. 34) Cotard zit. 1237. 35) Cramer 1043. 36) Dejerine 1974. 37) Derselbe 1060. 38) Dejerine et Serieux 2078. 39) Dejerine et Thomas 1979. 39a) Dieselben Rev. neurologique 1904. Nr. 13. 40) Dana u. Fränkel 1952. 41) Edgren, 2130. 42) Eichhorst, Korresp. f. schweiz. Ärzte 1886. 43) Ei senlohr 1092. 44) Ferrand zit. 102. (1399). 45) Francks zit. 102. 1399. 46) Fränkel 1088. 47) Fraser 1989. 48) Freund 1733. 49) Fritsch 1991. 50) v. Gehuchten et Goris 2079. 50a) Fumagalli, Rivist speriment. XVI. S. 485. 51) Giraudeau 1992. 52) Goetz zit. 1399. 53) Guenther, Zeitschr. f. klin.' Med. 1885. 54) Guéniot zit. 1237. 55) Hammond 1178. 56) Hecht, Thèse de Nancy 1887. 57) Hebold 1186. 58) Henneberg $2082 . \quad 59)$ Derselbe, Neurolog. Zentralbl. 1906, vgl. 2002a. 60) Heilly et Chantemesse 1196. 60a) Heil. bronner, Arch. f. Psych. 43. Heft 1 u. 2. 61) Henschen 1204. 62) Derselbe, Ups. läkareför. förh. 1886. 21. 63) Heubner 1209. 64) Hitzig 2000. 65) Joffroy 2002. 66) Jolly 1229. 67) Derselbe 2002a. 68) Derselbe, Neurolog. Zentralbl. 1899. S. 952. 69) Jordan zit. 93a. 70) Kahler, Prager med. Wochenschr. 1885. Nr. 16 u. 17. 70a) Derselbe, Prager Zeitschrift für Hlkde. 1880. 71) Kahler u. Pick 1237. 72) Kauders 2338. 73) Körner, 
Neurolog. Zentralbl. 1885. 73a) Derselbe, Otitische Erkrankungen des Gehirns usw. 74) H. Köster 1225. 75) Derselbe zit. Mendels Jahresber. 1899. 76) Kussmaul 1266. 77) Lacroix, Lyon médical 1890. LXV. 78) Lannois zit. Mendels Jahresber. 1897. 79) Laquer 2012. 79a) Lennmalm, Upsala Läkareför. Förhandl. 1885/86. XXI. 80) Leva, Virchows Arch. 1893. Bd. 132. 81) Lewandowsky, Zeitschr. f. klin. Medizin 1907. Bd. 64. 82) Lichtheim 1291. 83) Liepmann 1298. 84) Derselbe 2083. 2084. 84a) Derselbe, Journ. f. Psych. u. Neurol. 1907. 9. 10. 84b) Derselbe 2168 ff. 85) Lohmeyer, Arch. f. klin. Med. 13. S. 309. 86) Luys ref. Neurologisches Zentralbl. 1885. 86a) Luciani u. Seppilli, Lokalisation im Grosshirn. 1886. 87) Mader 2017. 88) Magnan 2018. 89) Mantle 1891. 90) Marie zit. 1399. 91) Mayor zit. 1237. 92) Mills 1370. 93) Meudel 2022. 93a) Mertens, Deutsche Zeitschrift für. Chirurgie. Bd. 60. 94) Mirallié 2024. 95) Moltgchanoff 1386. 96) v. Monakow, Ergebnisse der Physiologie. 1907. VI. 1 u.2. 97) Derselbe, Nothnagels Handbuch, Gehirnpathologie. 1905. 98) Derselbe, Arch. f. Psych. 1891. 23. Bd. 26. Bd. S. 97. 99) Derselbe, Neurol. Zentralbl. 1906. 956. 100) Derselbe, Arch. f. Psych. 16. S. 151 fl. 101) Mott 2026. 102) Naunyn 1399. 103) Netter 2027. 104) Nonne 2028. 105) Oppenheim, Charité-Annalen. X. S. 345. 105a) Derselbe, Lehrbuch der Nervenkrankheiten. 1906. 106) Osler, Amer. journ. of the med. sc. 1891. 107) Perret 2033. 108) Perroud 1429. 109) Pershing 2034. 110) Derselbe 1431. 111) Petrazzani, Rivista speriment. XII. pag. 86. 112) Petrina 1434. 113) Pick, Archiv f. Psych. 23. S. 896 fl. 114) Derselbe 1438. 115) Derselbe $1439 \mathrm{ff}$, , 116) Derselbe 2037. 117) Derselbe 2036. 117 a) Derselbe, Archiv f. Psych. Bd. 33. 118) Quensel 1468. 119) Derselbe 1468a. 120) Reinhard, Archiv f. Psych. Bd. 27 u. 28. F. 15. 121) Riedel zit. 157. 122) de Rode, Bullet de la soc. de méd. mentale VI. 1891. 123) Rose zit. 73 a. 124) Rosenthal 2042. 125) Sabourin zit. 1399 (162); zit. 76a. 126) Salomon zit. 93a. 127) Sander, Archiv für Psych. 2. 128) Sänger u. Sick 1527. 129) Sano 2044. 130) Derselbe 2045. 131) Schlöss 1533. 132) Schmidt, Zeitschr. f. Psych. Bd. 27. 133) Schmiegelow, Zeitschrift f. Nervenheilkde. 1895. 134) Schütz, Charité-Annalen 1888. 135) Seppilli.2047. 136) Derselbe zit. 2055; zit. 79 a. 137) Serieux 2048. 138) Serieux et Faranier 2092. 139) Serieux et Mignot 2050. 140) Scoresby Jackson, Edingburg med. Journ. Bd. XII. 1. II. pag. 696. 141) Senator 1543. 142) Shaw 1549. 142a) Derselbe, zit. Ferrier, On cerebr. localisat. 1890. 143) Skwortzoff 2054. 144) Sommer 1562. 145) Starr 2055. 146) Strohmayer 2056. 147) Tamburini 1590. 148) M. Thomas 2057. 149) Touche 2061. 150) Derselbe 1598. 151) Tripier, Rev. neur. de med. 1880. pag. 134. 152) Troisier zit. 157. 153) Trousseau 1606a. 154) Trucken. brodt, Zeitschr. f. Obrenheilkde. Bd. 44. 155) Vigouroux 2064. 156) Weiss 2067. 157) Wernicke, Lebrb. der Gehirnkrankheiten. 158) Derselbe 1632. 159) Wernicke u. Friedländer, Fortschr. d. Med. 1883. Nr. 6. 160) West, Brit. med. journal 1889. Nr. 7. 161) Westphal, Charité-Annalen. VII. Bd. S. 466. 162) Wiglesworth 2069. 163) Zacher, Arch. f. Psych. 22. Bd. 654. 164) Ziehl 2097. 165) Ziehen, Real-Encyklopädie d. Med. Art. Aphasie.

A n h ang.

1. Fälle, in denen die Beteiligung der Querwindung angegeben ist: 7, 26, 60,61 F. $41,66,67-59,78,94$ F. 29, F. 54,112 F. 1, F. 4, 116 F. 10, 118 A, 150 F. 3, 4, 5, 156, 158 F. 2, 160 . Diese Arbeit Fall 1. 
2. Fälle totaler Worttaubheit (ausser den im Text angegebenen) a) mit einseitigem Herde: 11, 14, 32 F. 1, 36, 39, 60, 68 F. 1, 88, 130, 156, 157 p. 182; b) mit doppelseitigem Herde: 3 F. 3, 8a, 64, 71 I, 92, 101, 111, 113, 116 F. 4, 159.

3. Verlust des Nachsprechens ist angegeben in Fällen von Worttaubheit a) bei einseitigem Herd: $36,39,60$. b) bei doppelseitigem: 3 F. 3, 8a, 71I, 92, 101, 116 F.4, 159. c) neben motorischer Aphasie oder zentraler Lähmung: 11. $59-67,88,149$ F.7, 150 F. 5 .

4. Neben Worttaubheit bestand

A. bei Zerstörung des Gyrus angularis

a) totale Alexie: $2,8,11,18,20,22,23,29$ F. $5,31,33,39 \mathrm{a}, 41,43$ F. 1 , 43 F. 2, 48I, 60, 61 F. 19, 61 II, 62, 65, 74, 77, 78, 100, 116 F. 10 , 117 a I, 125 , 134 F. 2, 141, 142, zit. $143,147,149$ F.4, 7,8, 150 F.1, 4,9, 161,162 .

b) partielle Alexie: $6,10,35,43,49,66,79,94$ F. 37, 50, 116 F.8, 9, 117 a II, 118, 121, 150 F. 23, 160, 161.

B. Ohne Zerstörung des Gyrus angularis.
a) Lautlesen ohne Sinnverständnis: $47,63,68$ F. 3, 76, 87, 88, 124, diese Arbeit F. 1.
b) Lesen grossenteils auch mit Verständnis: 3 F. 3, 28, 50, 55 F. 1, $84,92,241$.

5. In Fällen dauernder Worttaubheit bestanden
a) einseitige Herde bei progredientem Prozess: 75, 88, 135 F.1,2, 163 F.3.
b) doppelseitige Herde: 3 F. 3, 8a, 26, 48, 59-67, 711, 84, 86 a 2 Fälle, 92, 101, 111, 113, 116 F. 2, 9, 11, 136, 143a, 149 F.8, 159, 163 F. 3, diese Arbeit Fall 1 (100 u. 46).
c) grosser einseitiger Herd (links): 2 F. 1 u. 2, 9, 20, 23, 32 F. 2, 116 F. 8, 117 a II, 142.
d) desgleichen mit ausdrücklicher Erwähnung der Querwindung oder Insel : 7, 60, 66, 112 F. 1, 150 F. 5, 156, 158.
e) desgl. mit Zerstörung besonders auch des Stabkranzes: 11, 68I, 130, 149 F. 3, 150 F. 22 , 163 F. 2.

6. Fälle von Worttaubheit mit von der gewöhulichen abweichender Lokalisation des Herdes.
a) Wahrscheinlich war die erste Schläfen- oder Querwindung mit er- weicht bei 18,61 F. $75,147$.
b) Herde im Stabkranz oder im inneren Kniehöcker: 7, 61, 68 F. I u. II, 84, 122, 149 F. 3 u. F. 4, 150 F. 14.
c) tiefgreifende Herde im Gyrus supramarginalis: 110, 116 F. 11.
d) Fälle mit Tumoren, Abszessen oder sonst diffusen Veränderungen: 50, 52, 57, 69, 116 F. 2, F. 6, 123, 126, 133.
e) Unklare und veraltete Fälle: $13,19,55$ F. 2, 86, 90. 105, 127, 134 F.1,2, 143 (F. Magnan), 152, 161.

